\title{
Determination of material parameters for a unified viscoplasticity-damage model for a P91 power plant steel
}

\author{
Si Thu Kyaw*, James P Rouse, Jiawa Lu, Wei Sun \\ Faculty of Engineering, The University of Nottingham \\ University Park, Nottingham, NG7 2RD, UK
}

\begin{abstract}
*Corresponding author email: si.kyaw@nottingham.ac.uk
Address: C03, ITRC building, University Park, University of Nottingham, NG7 2RD
\end{abstract}

Phone: $+44-1159513811$

\begin{abstract}
Societal pressures are mounting on electricity operators to operate traditional fossil-fuel power plants in an efficient and flexible manner in conjunction with renewable power plants. This requires the uses of high frequency start up - shut down load profiles in order to better match market demands. As such, high temperature/pressure components such as steam pipe sections and headers experience fluctuating mechanical and thermal loads. There is therefore an industrial need for the accurate prediction of fatigue and creep damage in order to estimate remnant component life. In the present work, a continuum damage model has been coupled with a Chaboche unified viscoplastic constitutive model in order to predict stress-strain behaviour of a P91 martensitic steel (a material used for power plant steam pipes) due to cyclic plasticity and damage accumulation. The experimental data used here are from the previous work [1]. Cyclic fully reversed strain controlled experiments $( \pm 0.4 \%, \pm 0.25 \%$ and $\pm 0.2 \%$ strain ranges) and cyclic test with a dwell period ( $\pm 0.5 \%$ strain ranges) for a $\mathrm{P} 91$ martensitic steel under isothermal conditions $\left(600^{\circ} \mathrm{C}\right)$ are utilised. The physically relevant material parameters are determined and optimised using experimental results. Although many material parameter identification procedures can be found in the literature [1-6], there are uncertainties in determining the limits for the parameters used in the optimisation procedure. This could result in unrealistic parameters while optimising using experimental data. The issue is addressed here by using additional dwell test to identify the limits for stress relaxation parameters before using Cottrell's stress partition method to identify the limits for strain hardening parameters. Accumulated stored energy for damage initiation criterion and damage evolution parameters are also extracted from the experimental results. The estimated failure lifetimes for $\pm 0.4 \%, \pm 0.25 \%$ and $\pm 0.2 \%$ cases are 1600,4250 and 9500 cycles, respectively, as opposed to 1424,3522 and 10512 cycles as given by experiments.
\end{abstract}

Keywords: P91 steel, low cycle fatigue, unified viscoplasticity model, continuum damage, life prediction 


\section{Introduction}

P91 (9-12\% Cr martensitic) steel has been used extensively as a major power plant material in many high temperature applications such as steam pipes and headers. This material was originally developed to achieve high creep strength at high temperature for maximum thermal efficiency [7, 8] (this is beneficial for the traditional baseline operating conditions of fossilfuel power plants). Corrosion resistance of P91 steel for steam environment has also been shown to be better than more conventional austenitic steels [9]. Present operation trends aim to reduce carbon emissions; therefore renewable energy power plants have become prominent and thermal plants are expected to operate intermittently. Due to the intermittent nature (repeated start-stop operations and two shifting [10]) of these generation requirements power plant components are subjected to thermo-mechanical fatigue (TMF) loads. Hence, it is important to predict mechanical response and lifetime of P91 under such conditions (and to investigate the suitability of P91 for power plants under intermittent loading). In this paper, a constitutive model will be applied to model the stress-strain response of P91 under uniaxial fatigue loading at an elevated temperature. The model also takes account of evolution of the microstructural damage which eventually leads to failure at the continuum level.

Generally, stress-strain behaviour of the material under TMF at high temperature can be divided into two stages. In the first stage plasticity and viscous effects modify stress-strain response of the material while voids and microcracks form simultaneously. These microstructural defects affect macroscopic stress-strain response only during the second stage. Cyclic plasticity has received a large amount of attention from numerous authors and has been modelled numerically using a variety of methods. Simple kinematic terms, for example, have been suggested by Prager [11] and Ziegler [12]. These were extended to include cyclic hardening phenomenon (such as the Bauschinger effect) in the multi surface models [13]. For high temperature applications, viscous stress accumulation must also be considered. For this purpose, many unified viscoplastic models such as Bodner and Partom [14], Krempl et al. [15], and Chaboche models [16] were proposed. Chaboche model is chosen for the current work since the model can also be applied to the second stage of material response under TMF with minimum modifications. The model has been applied to different types of materials in the past. Tong et al. [5] used uniaxial Chaboche model to model cyclic inelastic behaviour of a nickel based alloy. Saad et al. [1] and Hyde et al. [17] used the similar model to analyse evolutions of initial stress range of P91 steel and 316 
stainless steel under strain controlled TMF load. The model was modified by Barrett et al. [2] for multiaxial TMF problems which are independent of applied strain rate using a hyperbolic sine viscoplastic model. Multiaxial Chaboche model has also been used by Koo and Kwon [3] and Zhang et al. [18] for cyclic plasticity modelling of martensitic steels. Bernhart et al. [19] implemented isotropic hardening strain memory effect within multiaxial Chaboche model for forging tool steel. In common, these constitutive models have first order differential equations which include material parameters for time-dependent stress-strain behaviour. It is necessary to estimate these material parameters from available experimental hysteresis loops and optimise them in order to fit numerical results to experimental data. However, a careful procedure for estimation of ranges for initially estimated parameters is required. Otherwise, the parameters obtained will be physically unrealistic although numerical results could fit experimental data. This parameter identification procedure using the stress partition method [20] for P91 steel is presented in this paper.

Historically, damage under combined creep-fatigue loads has been estimated by superimposing two different damage components from creep and fatigue tests. Taira rule [21] is one of the earliest example. Wang et al. [22] and Zhang et al. [23] applied accumulated damage theory for which damage parameter is the sum of pure creep and pure fatigue damage parameters. The accumulation could be either linear or non-linear relationship. However, these models could not capture the actual interaction damage from creep and fatigue. For example, grain boundary cavities caused by creep damage could accelerate fatigue damage [24]. On the other hand, surface cracks due to fatigue could be blunted by creep damage during hold periods, deaccelerating damage accumulation [25]. To simulate interaction damage given by a total inelastic strain (both plastic and creep strains), continuum damage mechanics (CDM) approach based on total inelastic strain is applied in this study. The concept was initially proposed as CDM approach for creep damage by Kachanov [26]. It assumes that heterogeneous behaviour of a material due to micro-defects can be averaged within a representative volume element (RVE) and the averaged material property is treated as that of a homogenous material with the same volume. The size of RVE is often taken at the order of $0.1 \mathrm{~mm}^{3}$ [27]. In addition to limit on RVE size, CDM imposes various restrictions on the complexity of the strain paths at microscopic levels due to micro-defects [28, 29]. Therefore, alternative non local damage approach has been proposed $[30,31]$ to model macroscopic stress-strain behaviour as volume average of microscopic cells over a RVE. 
However, the approach proves to be challenging for large scale engineering problems in terms of boundary conditions at different scale levels [32], executing time and computational power [33] and validation of numerical method [34]. Hence, continuum analysis is still a preferred choice for engineering design problems and it will be applied for the current study.

For the current work, the Chaboche constitutive model is modified by using effective stress term which is related to volume loss from damage. Constitutive models used for this paper is described in detail in Section 2. Section 3 describes experiments and corresponding data used in this study to determine viscoplastic material parameters of P91 steel by using Cortrell's partition method and an optimisation procedure which can be found in Section 4.

It is necessary to define the point within Chaboche model at which damage initiation occurs to modify effective stress due to damage evolution. Within a thermodynamic framework, damage initiation point can be linked to either accumulated inelastic strain or accumulated stored energy during load $[35,36]$. The former criterion for damage initiation is not only dependent on temperature but also on the loading profiles [37]. Hence, accumulated stored energy criterion is used in this work as a threshold parameter for damage initiation. From experimental fatigue data, damage process can be illustrated from the reduction in elastic modulus $[24,37]$. The loss in modulus is expected since the volume of the specimen is reduced due to voids and microcracks formations. Based on this concept, damage evolution law can be deduced empirically from the evolution of elastic modulus. Identifications of damage initiation and evolution parameters are described in Section 5. Finally, comparisons of hysteresis stress-strain loops and lifetime for isothermal fatigue tests of $\mathrm{P} 91$ at $600^{\circ} \mathrm{C}$, given by the numerical model, are compared to corresponding experimental data in Section 6 .

\section{Material models to simulate cyclic damage of P91 under high temperature}

\subsection{Chaboche unified viscoplasticity model}

A constitutive equation is necessary to carry out any structural analysis as it provides the material dependent relationship between stress and strain for a particular loading condition. Here, the Chaboche unified viscoplastic constitutive equation presented in [38] is used to represent the cyclic material hardening response of a P91 steel. The current model will be limited to studies at continuum material level and for quasi-static loading (allowing loading 
rate dependency to be neglected in the material model). The model unifies all inelastic strains (plasticity and creep strains) of materials into one viscoplastic strain (which will be simply called plastic strain in this paper). The relationship of viscoplastic strain rate $\left(\dot{\varepsilon}_{p}\right)$ to total stress for an uniaxial case can be expressed by power law relationship as below:

$$
\begin{gathered}
\dot{\varepsilon}_{p}=\left(\frac{f}{Z}\right)^{n} \operatorname{sign}(\sigma-\chi) \\
f=|\sigma-\chi|-R-k
\end{gathered}
$$

where $\mathrm{Z}$ and $\mathrm{n}$ are material parameters that describe the evolution of the viscous stress $\sigma_{v}$. Eq (2) is known as a yield function and determines the elastic limit; the material yields when $\mathrm{f}$ is equal to zero. The yielding point depends on kinematic hardening $(\chi)$, isotropic hardening $(\mathrm{R})$ parameters which change due to inelastic loading (the present state of the material therefore depends on its loading history through these quantities) and the constant cyclic yield strength (k) (the initial size of the yield locus). In the deviatoric stress plane, kinematic hardening represents a displacement of the centre of yield locus and isotropic hardening represents an expansion of the yield locus ( $\chi$ and $\mathrm{R}$ also known as back stress and drag stress, respectively). Drag stress evolution can be expressed in terms of accumulated plastic strain using:

$$
\dot{R}=(b(Q-R)+H(1+b p)) \dot{p}
$$

$\mathrm{Q}$ is the stabilised value of $\mathrm{R}$ after a specific accumulation of plastic strain and $\mathrm{b}$ determines how quickly $\mathrm{R}$ is stabilised. $\mathrm{H}$ specifies the linear evolution of drag stress which is proportional to $\mathrm{p}$. The accumulated plastic strain $\mathrm{p}$ for each fatigue cycle is equal to $2 \times \Delta \varepsilon_{\mathrm{p}}$ under uniaxial loading conditions. $\Delta \varepsilon_{\mathrm{p}}$ is the plastic strain range of a fatigue cycle.

Rate of back stress evolution can be expressed as:

$$
\dot{\chi}=\mathrm{C}\left(\mathrm{a} \dot{\varepsilon}_{\mathrm{p}}-\chi \dot{\mathrm{p}}\right)
$$

where a and $\mathrm{C}$ are material parameters that are similar in nature to $\mathrm{b}$ and $\mathrm{Q}$ in the isotropic hardening law. More than one back stress term is often applied to allow for different stabilisation rates of different back stress components. Back stress components can be summed in order to approximate the overall material behaviour (this generally provides a 
better fit to experimental results [39]). Two back stresses are used for current study. Since back stress is a function of $\varepsilon_{\mathrm{p}}$ it is periodic if cyclic loading is applied. On the other hand, drag stress depends on the scalar accumulated plastic strain $\mathrm{p}$ and hence is a monotonic quantity (decreasing or increasing depending on whether the material is cyclically softening or hardening, respectively).

The applied stress for a pure elastic-plastic case can be obtained by rearranging the yield function of Eq (2) at the point of yielding. For viscoplastic cases however, the total stress has an additional viscous stress component $\left(\sigma_{v}\right)$. A power law relationship is commonly used for this viscous stress as shown in Eq (5). Finally, total stress in the viscoplastic case can be expressed as shown in Eq (6). Note that total stress can also be related to total strain $(\varepsilon)$ as using Eq (7).

$$
\begin{gathered}
\sigma_{\mathrm{V}}=\mathrm{Z} \dot{\mathrm{p}}^{1 / \mathrm{n}} \\
\sigma=\left(\mathrm{k}+\mathrm{R}+\sigma_{\mathrm{V}}\right) \operatorname{sign}(\sigma-\chi)+\chi \\
\sigma=\mathrm{E}\left(\varepsilon-\varepsilon_{\mathrm{p}}\right)
\end{gathered}
$$

Eqs (1) to (7) form a set of constitutive equations for stress-strain relationships of the material under uniaxial cyclic loading.

\subsection{Chaboche viscoplasticity model coupled with continuum damage model (CDM)}

When the material is subjected to cyclic loading at high temperature, damage develops due to nucleation and propagation of microcracks and voids [37]. It is assumed that damage does not affect macroscopic mechanical behaviours of materials during the incubation period. The damage incubation period is often associated with accumulated plastic strain levels within the material. Once a certain level of accumulated plastic strain is reached, the damage induced will cause changes in the macroscopic behaviour of materials; most noticeably a reduction in effective elastic modulus. If damage is assumed to be isotropic and to represent the ratio of damaged (void) area to undamaged area in the RVE, Hooke's law of elasticity may be coupled with damage for the uniaxial cases using Eq (8). 


$$
\varepsilon=\frac{\sigma}{(1-D) E}=\frac{\sigma}{\widetilde{E}}
$$

where $\mathrm{E}$ is the initial elastic modulus of the material and $\widetilde{E}$ is the effective modulus of the damaged material. The magnitude of damage can therefore be observed indirectly from changes in elastic modulus between loading cycles.

Once damage has initiated, Chaboche constitutive equations from Section 2 need to be modified accordingly. To avoid significant modification, the effective stress concept described in the work of Lemaitre [37] is used in this study. Once damage has initiated, the total area subjected to load is reduced due to the formation of micro cavities and cracks. The total effective stress ( $\tilde{\sigma})$ needs to take account of this effect and for isotropic damage it can be related to the stress without damage $(\sigma)$ by Eq (9). This effective stress will be used for Chaboche constitutive equations after damage initiates.

$$
\tilde{\sigma}=\frac{\sigma}{1-\mathrm{D}}
$$

Prior to damage, the plastic multiplier $(\lambda)$ used for both kinematic and isotropic hardening, is equivalent to accumulated plastic strain (p) and hence derivation of constitutive equation was made using $\mathrm{p}$ as shown in Eqs (1) to (7). After damage, it can be proved [36] that $\lambda$ is related to $\mathrm{p}$ by $\mathrm{Eq}(10)$.

$$
\dot{\lambda}=\dot{p}(1-D)
$$

Finally, a set of constitutive equations for Chaboche model coupled with damage may be derived (see Eqs (11) to (16)).

$$
\begin{gathered}
\dot{\varepsilon}_{\mathrm{p}}=\left(\frac{\mathrm{f}}{\mathrm{Z}}\right)^{\mathrm{n}} \operatorname{sign}(\sigma-\chi) \\
\mathrm{f}=|\tilde{\sigma}-\chi|-\mathrm{R}-\mathrm{k} \\
\dot{\chi}=C\left(a \dot{\varepsilon}_{\mathrm{p}}(1-\mathrm{D})-\chi \dot{\mathrm{p}}(1-\mathrm{D})\right)
\end{gathered}
$$




$$
\begin{gathered}
\dot{R}=(b(Q-R)+H(1+b p)) \dot{p}(1-D) \\
\sigma_{v}=Z(\dot{p})^{1 / n} \\
\sigma=\left(\mathrm{k}+\mathrm{R}+\sigma_{\mathrm{V}}\right) \operatorname{sign}(\sigma-\chi)+\chi=\mathrm{E}\left(\varepsilon-\varepsilon_{\mathrm{p}}\right)
\end{gathered}
$$

To use the above constitutive model, elastic and viscoplastic material parameters and continuum damage model parameters must be determined. These properties are identified and subsequently optimised to fit experimental LCF test results as discussed in Sections 4 and 5.

\section{Low cycle fatigue experiments of P91 under isothermal condition}

\subsection{Experimental set-up}

If the applied strain is large enough to cause significant plastic strain within a cycle and if the specimen fails after less than $10^{4}$ cycles, the material is assumed to respond due to LCF deformation and failure mechanisms. For the present study, three fully reversed $(\mathrm{R}=-1)$ uniaxial and isothermal strain controlled tests with total strain ranges of $\pm 0.2 \%, \pm 0.25 \%$ and $\pm 0.4 \%$ were completed at $600^{\circ} \mathrm{C}$, allowing for the study of LCF in a P91 steel at high temperature. A constant strain rate of $0.1 \% \mathrm{~s}^{-1}$ was used in all tests and cycle durations for the $\pm 0.2 \%, \pm 0.25 \%$ and $\pm 0.4 \%$ cases are $8 \mathrm{~s}, 10 \mathrm{~s}$ and $16 \mathrm{~s}$, respectively. In addition, a LCF test with a dwell period was carried out to obtain viscoplastic parameters. For the dwell test, a strain range of $\pm 0.5 \%$ is used. The strain rate to maximum strain is $0.1 \% / \mathrm{s}$ similar to other LCF tests. At maximum strain, stress is allowed to relax while holding the total strain constant before unloading. The loading cycles for $0.4 \%$ LCF test and $0.5 \%$ LCF test with dwell time are shown in Fig. 1. The specimen geometry for all the tests is given in Fig. 2. The material used for the current work is P91 steel and its chemical composition is given in Table 1. The specimens were machined from power plant steam pipe sections with an outer diameter of $298.5 \mathrm{~mm}$ and a wall thickness of $55 \mathrm{~mm}$. The material was austenised at $1060^{\circ} \mathrm{C}$ for $45 \mathrm{~min}$ and tempered at $760^{\circ} \mathrm{C}$ for $2 \mathrm{~h}$. 


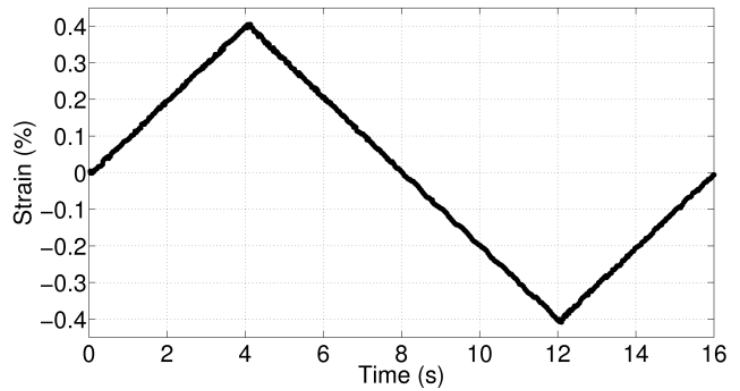

(i)

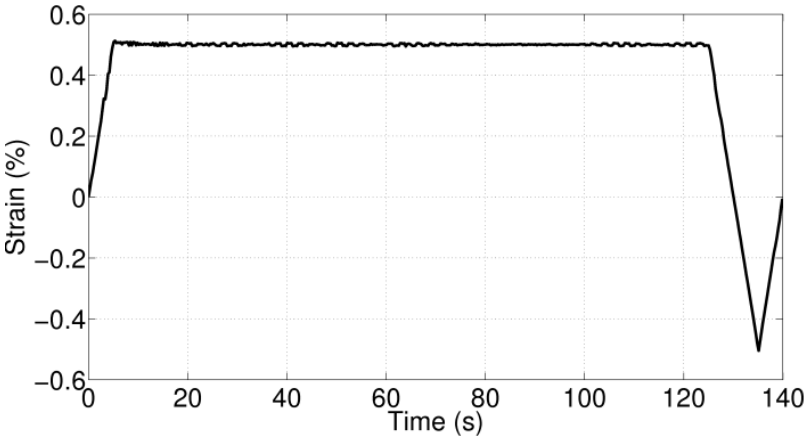

(ii)

Fig. 1: Loading profile for (i) $0.4 \% \mathrm{LCF}$ test and (ii) $0.5 \% \mathrm{LCF}$ test with dwell time

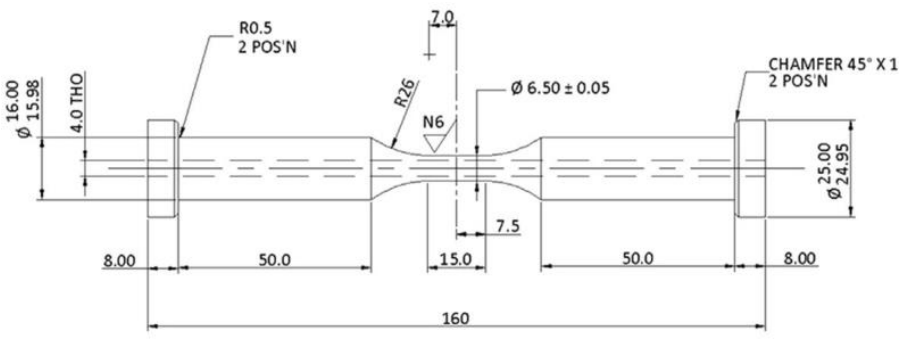

Fig. 2: Geometry of the uniaxial specimen used for isothermal experiments (dimensions in $\mathrm{mm}$ )

Table 1: Chemical compositions of the P91 steel (wt\%)

\begin{tabular}{ccccccccccc}
\hline $\mathrm{Cr}$ & $\mathrm{Mo}$ & $\mathrm{C}$ & $\mathrm{Si}$ & $\mathrm{S}$ & $\mathrm{P}$ & $\mathrm{Al}$ & $\mathrm{V}$ & $\mathrm{Nb}$ & $\mathrm{N}$ & $\mathrm{W}$ \\
\hline 8.6 & 1.02 & 0.12 & 0.34 & $<0.002$ & 0.017 & 0.007 & 0.24 & 0.07 & 0.06 & 0.03
\end{tabular}

\subsection{Experimental results}

A typical stress-strain loop obtained from the experimental results is shown for the first cycle of the $\pm 0.4 \%$ strain range $(\Delta \varepsilon)$ case in Fig. 3. Several important material properties can be extracted from this type of hysteresis loop. For example, the slope of the line OA shown in Fig. 3 can be taken as the elastic modulus for first loading cycle and the stress $\mathrm{k}$ (at which a non-linear stress-strain relationship starts) can represent the cyclic yield strength of the material. Total strain range $(\Delta \varepsilon)$ can be decomposed into plastic strain range $\left(\Delta \varepsilon_{\mathrm{p}}\right)$ and positive and negative elastic strains $\left(\varepsilon_{e l}^{+}\right.$and $\left.\varepsilon_{e l}^{-}\right)$. Positive and negative elastic strains are related to compressive and tensile parts of a loading cycle, respectively. As mentioned in Sectoin 2.2, $\Delta \varepsilon_{\mathrm{p}}$ for this work includes all inelastic strains (both plastic and viscous). As the loading cycles accumulate, plastic strain is also accumulated and can be related to cyclic 
plasticity material parameters and material damage parameters as described in Section 2. For each cycle, the accumulated plastic strain (p) is given by $2 \times \Delta \varepsilon_{\mathrm{p}}$. For P91, the plastic strain range $\left(\Delta \varepsilon_{\mathrm{p}}\right)$ ascends rapidly and continues to increase at a slower rate before it stabilises (see Fig. 4).

As the material hardens (or softens) during a fatigue test, the stress amplitude $\left(\frac{\sigma_{\max }-\sigma_{\min }}{2}\right)$ increases or decreases, respectively. For P91, significant overall reduction of stress amplitude is observed for all strain ranges tested (see Fig. 5). Stress-strain behaviour of the material under LCF loading can be divided into two stages. The stress amplitude is modified in Stage I by cyclic plasticity. In the undamaged region, the material experienced an initial rapid nonlinear softening region (stage I (i)) followed by a steady state linear decrease (stage I (ii)). Several pieces of microstructural evidence [40-42] were proposed in literature for the cause of macroscale softening of P91 steel during stage I of damage (subgrain coarsening, a decrease in dislocation density and precipitate coarsening). After cyclic plasticity is stabilised, a rapid decrease in stress amplitude, which is caused by the formation and coalescence of microstructural defects, occurs approximately at $70 \%$ of the failure life and marks the onset of stage II (Fig. 5). The number of cycles to failure $\left(N_{f}\right)$, according to BS ISO 12111:2011 [43], for the test can be determined by noting the cycle at which a 10\% stress drop from the stabilisation curve of cyclic plasticity is observed (see Fig. 6). Using this method, $N_{f}$ for $\pm 0.4 \%, \pm 0.25 \%$ and $\pm 0.2 \%$ cases are 1424,3522 and 10512 cycles, respectively.

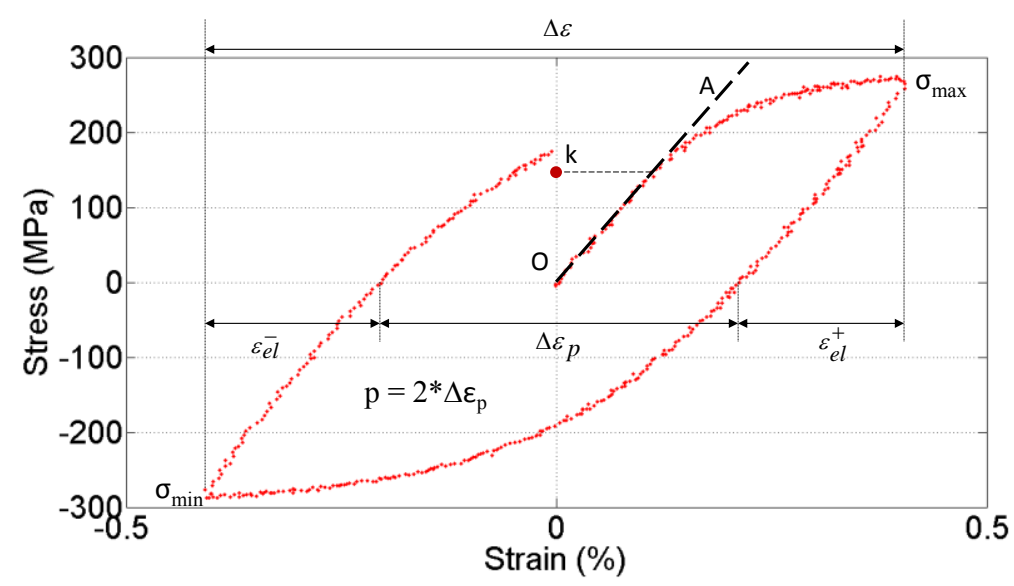

Fig. 3: Stress-strain loop of first cycle of $\mathrm{P91}$ at $600^{\circ} \mathrm{C}$ with $\pm 0.4 \%$ total strain amplitude. 


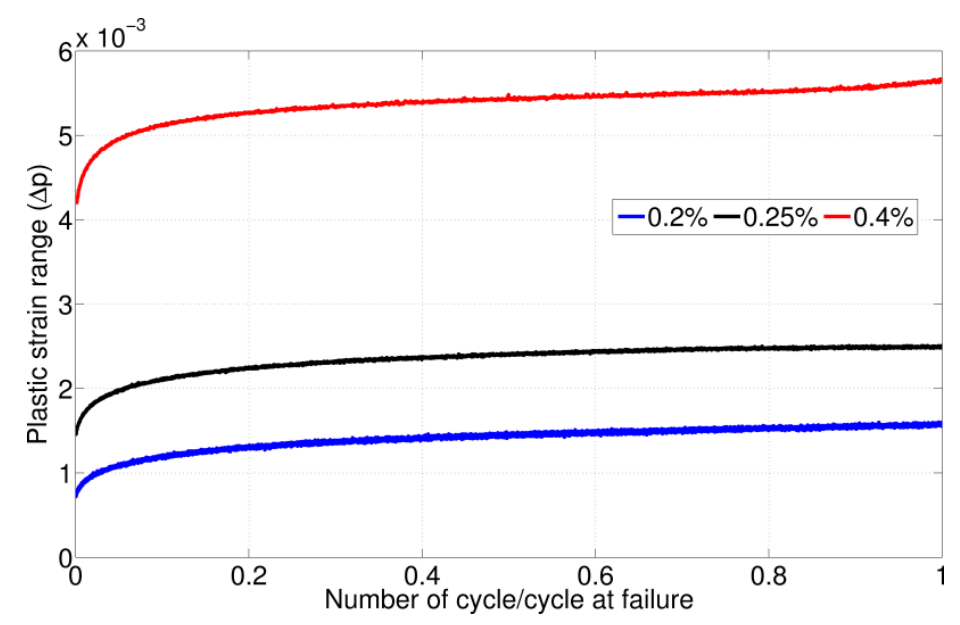

Fig. 4: Plastic strain range $\left(\Delta \varepsilon_{\mathrm{p}}\right)$ against number of cycles for $\mathrm{P91}$ at $600^{\circ} \mathrm{C}$ for different total strain amplitudes [39].

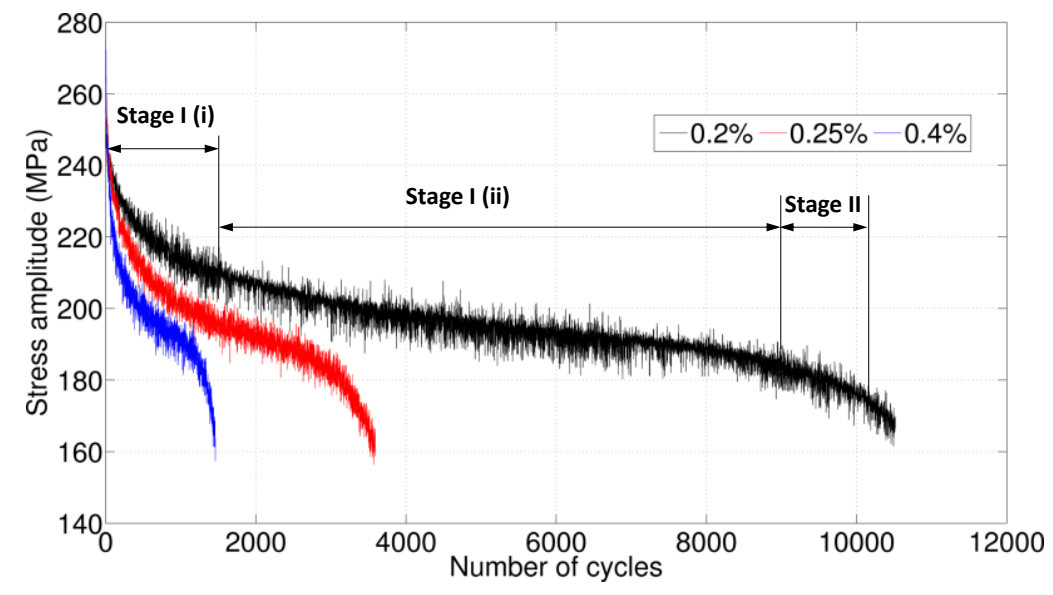

Fig. 5: Stress amplitude against number of cycles for at different total strain amplitudes (showing two stages of stress amplitude evolution for $\pm 0.2 \%$ case) [39].

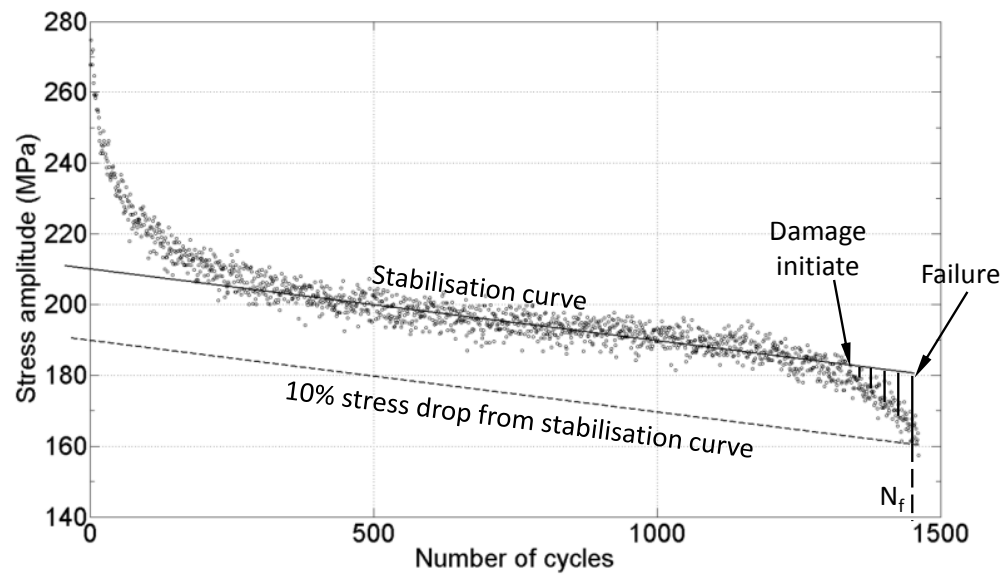

Fig. 6: $10 \%$ stress drop criterion used to determine failure cycle $\left(N_{f}\right)$ for $\mathrm{P} 91$ at $600{ }^{\circ} \mathrm{C}$ for $\pm 0.4 \%$ case. 


\section{Determination of Charboche's material parameters of P91}

The Chaboche model with and without CDM has been defined in Section 2. It is clear that the hardening/softening and damage behaviours of a material is dependent on the evolution of several internal state variables $\left(\chi, \mathrm{R}, \sigma_{\mathrm{v}}\right.$, and $\left.\mathrm{D}\right)$. The evolution of each of these state variables is dependent on empirical functions containing temperature and material dependent coefficients which must be determined from experimental data (shown in Section 3) before the model can be used. Initial estimates for the material constants were obtained by analysing experimental results and an optimisation process was conducted to fit the model to the experimental data.

The main problem encountered when optimising material parameters for LCF test is uncertainty of the bounds for material parameters optimised. Hence, allowing a wide range for one set of parameters will fit the experimental data accurately while the obtained parameters could be unrealistic. For example, R value should not exceed the cyclic yield strength to ensure a non-zero yield surface of the material. In the same manner, allowing a wide range for Norton creep parameters and kinematic hardening parameters could result in high viscoplastic stress with no kinematic hardening at all or vice versa while total stress obtained from both scenarios could fit the experimental stress. Hence, it is useful to gain some understanding of the development and magnitude of the state variables from the experimental data to assist in determining initial estimates of the material constants and in defining the objective functions for the optimisation procedure. Cottrell's stress partitioning method [44] provides a utility to achieve this and will be briefly summarised here with respect to the isothermal fully reversed uniaxial data used in the present work (see Fig. 7).

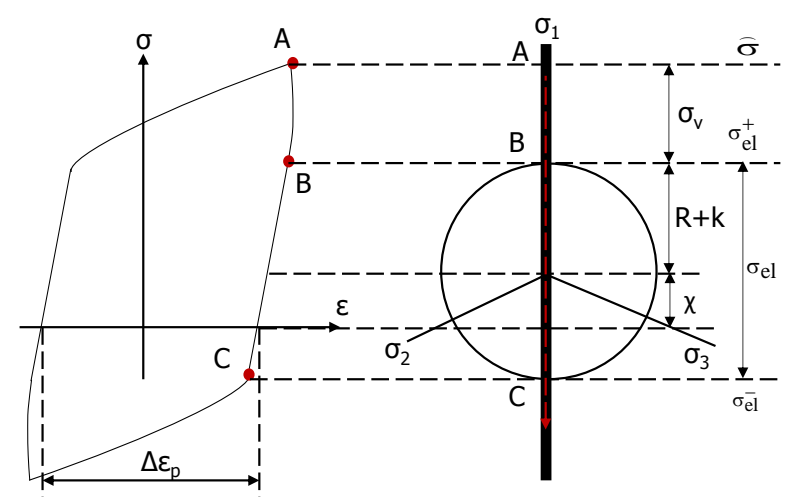

Fig. 7: A schematic representation of Cottrell's stress partitioning method, showing the stress regions on both a hysteresis loop for a LCF test and the corresponding yield surface 
Considering the unloading (compressive) loading region, the stress point lies initially outside of the yield surface due to viscous effects. This is shown by point $\mathrm{A}$ in Fig. 7 (note that the uniaxial stress path is shown by a red dashed line). After a period of stress relaxation (nonlinear stress-strain behaviour), the stress point re-joins the yield surface (point B and stress $\sigma_{e l}^{+}$in Fig. 6) and, under continued unloading, traverses the yield surface (representing elastic deformation of the material). When the stress point reaches the compressive yield stress (point $\mathrm{C}$ and stress $\sigma_{e l}^{-}$) compressive visco-plastic deformation begins and the stress point may once again leave the yield surface as the state variables (and hence yield surface itself) evolve. Assuming an isotropic yield surface (distortional/rotational hardening has been neglected), knowledge of the magnitude and location of the elastic region ( $\sigma_{e l}$, points B to $\mathrm{C}$ ) allows the state variables to be isolated based on their definitions (shown in Eqs (17)-(19)). The method may be easily reversed to determine state variable values in the tensile loading region. Values of plastic strain may be found directly from the hysteresis loop (see Fig. 7).

$$
\begin{gathered}
\sigma=\hat{\sigma}-\sigma_{\mathrm{el}}^{+} \\
\mathrm{R}+\mathrm{k}=\frac{\sigma_{\mathrm{el}}}{2} \\
\chi=\sigma_{\mathrm{el}}^{+}-\frac{\sigma_{\mathrm{el}}}{2}
\end{gathered}
$$

As shown in Fig. 7, to obtain state variables for Chaboche's model, a linear elastic region (BC) needs to be separated from the unloading curve (AC). If LCF test data without a dwell period is used, finding stress relaxation curve $\mathrm{AB}$ is challenging. If LCF test data with a dwell period is used, stress relaxation region (characterised as a vertical line AB) for viscous stress $\left(\sigma_{\mathrm{v}}\right)$ is more prominent as shown in Fig. 8. Region BC is an elastic unloading region and it represents twice of the elastic domain while $\chi$ can be found from the shift of centre of yield surface as shown in Fig. 8. The procedure is applied to the experimental data of LCF test (strain range $\pm 0.5 \%$ ) with a dwell period and evolutions of $\mathrm{R}, \chi$ and $\sigma_{\mathrm{v}}$ against accumulated plastic strain are shown in Fig. 9. Note that damage region (Stage II) is omitted in this plot. It can be observed that $\sigma_{\mathrm{v}}$ remains constant throughout apart from early cycles with peak stresses higher than $275 \mathrm{MPa}$. 


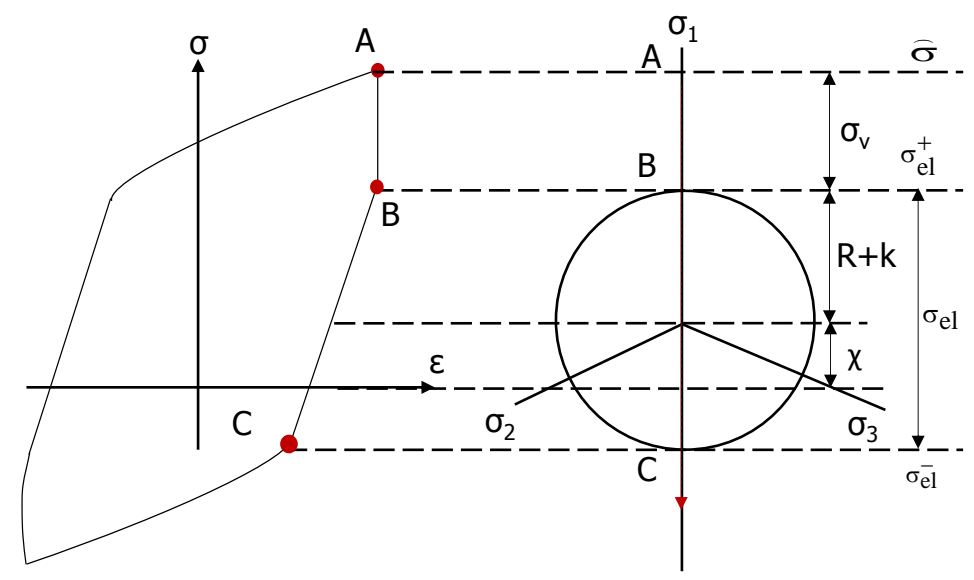

Fig. 8: A schematic representation of Cottrell's stress partitioning method applied on a hysteresis loop for a LCF test with dwell time

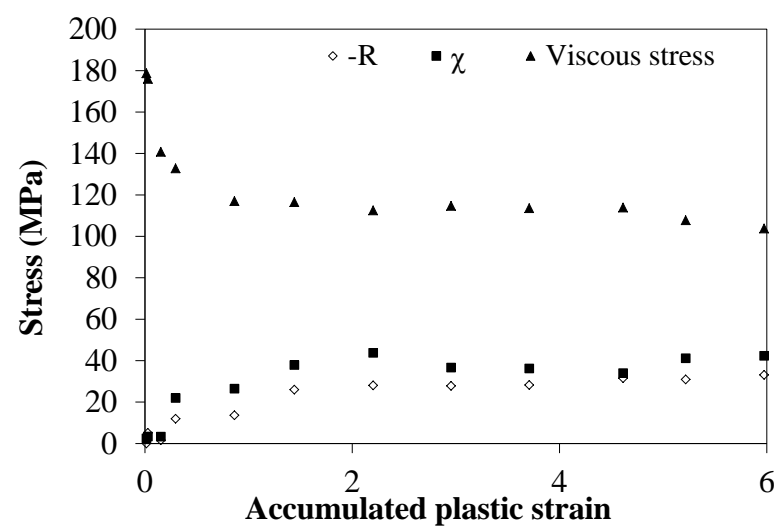

Fig. 9: Initial estimations of state variables of $\mathrm{P91}$ at $600^{\circ} \mathrm{C}$ and $\pm 0.5 \%$ strain range with dwell using Cottrell stress partition method [44]

As shown in Fig. 9, isotropic softening is expected for P91 since the R value decreases with time. This softening causes a reduction in stress amplitude $\left(\Delta\left(\sigma_{\max }-\sigma_{\min }\right)\right)$. However, the amount of softening is not identical for all strain ranges as the reduction of $\Delta\left(\sigma_{\max }-\sigma_{\min }\right)$ is not the same for tests with different strain ranges (see Fig. 10). Evidences of the dependence of isotropic softening on applied strain range has also been found in a study carried out by Fournier et al. [42]. Fournier observed that sub-grain coarsening, which is responsible for isotropic softening, is dependent on the strain range applied and subgrain size is directly proportional to the strain range applied for LCF test.

Assuming that the viscous stress relaxes during unloading and it is independent of the peak stress, isotropic softening parameters $(\mathrm{Q}, \mathrm{b}, \mathrm{H}$ from $\mathrm{Eq}(3))$ can be estimated from the change in stress amplitude $\left(\Delta\left(\sigma_{\max }-\sigma_{\min }\right)\right)$ by equating it to isotropic stress term (R). $\Delta\left(\sigma_{\max }-\sigma_{\min }\right)$ 
against accumulated plastic strain plots for three different strain ranges are shown in Fig. 10. Isotropic term (R) is obtained by integrating Eq (3) as shown in Eq (20) and it is fitted to the change in stress amplitude curves shown in Fig. 10 to obtain the initial estimates of the isotropic softening parameters.

$$
\mathrm{R}=\mathrm{Q}\left(1-\mathrm{e}^{-\mathrm{bp}}\right)+\mathrm{Hp}
$$

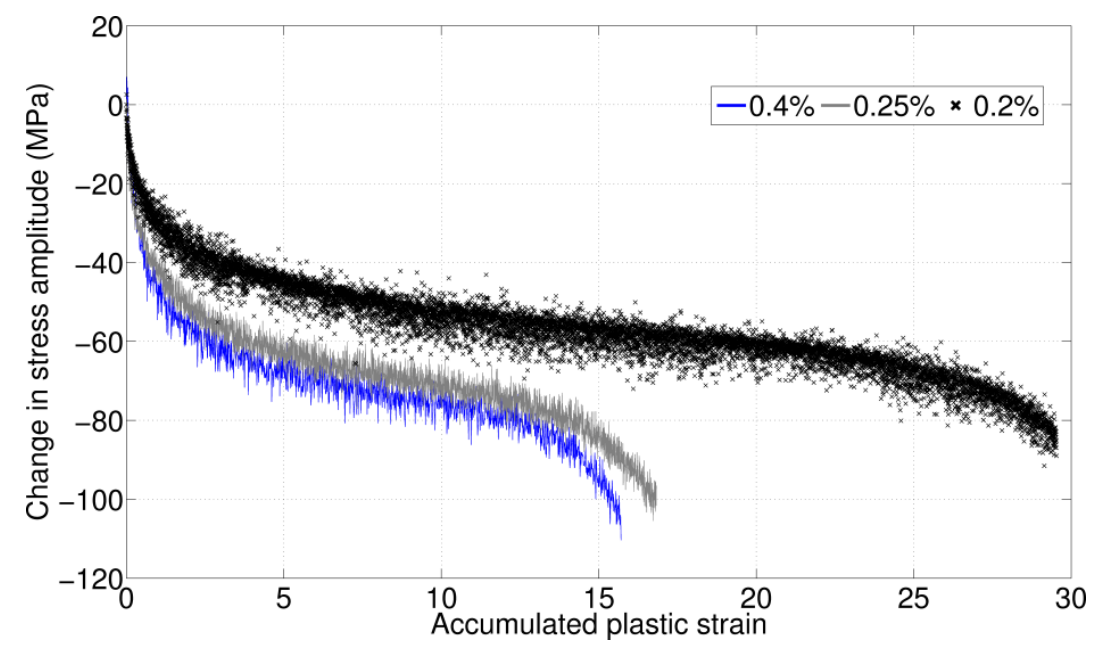

Fig. 10: Stress amplitude changes of $\mathrm{P91}$ at $600^{\circ} \mathrm{C}$ for $\pm 0.4 \%, \pm 0.25 \%$ and $\pm 0.2 \%$ strain ranges.

Although there are experimental based evidences for the relationship between isotropic softening and applied strain range, no actual evidence can be found for kinematic hardening behaviour of P91. For the current case, it is assumed that kinematic hardening is strain range independent and initial estimates are taken from stress partition results shown in Fig. 9 with $\pm 15 \mathrm{MPa}$ error for the total kinematic stress.

Initial estimates of power law parameters for a viscoplastic law ( $Z$ and $n$ shown in Eq. (5)) are obtained from the stress relaxation region (shown as $\mathrm{AB}$ in Fig. 8) of the first cycle of the dwell test. Total stress relaxation with time for a region AB is shown in Fig. 11. A procedure for obtaining estimates of $\mathrm{Z}$ and $\mathrm{n}$ from this stress relaxation curve will be outlined here.

During stress relaxation stage, total strain rate can be written as:

$$
\dot{\varepsilon}_{\text {total }}=\dot{\varepsilon}_{\mathrm{p}}+\dot{\varepsilon}_{\mathrm{e}}
$$


As the total strain is kept constant during the relaxation region, total strain rate is zero. Hence total plastic strain rate becomes:

$$
\dot{\varepsilon}_{\mathrm{p}}=-\dot{\varepsilon}_{\mathrm{e}}=-\frac{\dot{\sigma}}{\mathrm{E}}
$$

Using power law relationship for plastic strain rate:

$$
\left(\frac{\mathrm{f}}{\mathrm{Z}}\right)^{\mathrm{n}}=-\frac{\dot{\sigma}}{\mathrm{E}}
$$

where $\mathrm{f}$ is the yield function written as:

$$
\mathrm{f}=\sigma-\chi-(\mathrm{R}+\mathrm{k})
$$

Assuming kinematic $(\chi)$ and isotropic stresses (R) are kept constant during the stress relaxation period, do/dt will be equal to $\mathrm{df} / \mathrm{dt}$. Finally, Eq (23) can be integrated as:

$$
\int_{f\left(t_{0}\right)}^{f\left(t_{\text {final }}\right)}(f)^{n} d f=-\int_{t_{0}}^{t_{\text {final }}} z^{-n} E d t
$$

$\mathrm{f}(\mathrm{t})$ can be expressed as:

$$
f(t)=\left[\frac{f\left(t_{0}\right)}{\left(z^{-n} E t(n-1)\left(f\left(t_{0}\right)\right)^{n-1}+1\right)^{\frac{1}{n-1}}}\right]
$$

To plot $\mathrm{f}(\mathrm{t})$ against time, kinematic and isotropic stresses have to be known. It is assumed that the size of yield surface is unchanged during the first step by isotropic hardening and hence $\mathrm{R}=0$. Therefore, $\chi$ can vary from zero (no hardening) to $\sigma\left(\mathrm{t}_{\text {final }}\right)-\mathrm{k}$ (stress is relaxed completely to cyclic yield point). Initial estimates of $\mathrm{k}$ and $\mathrm{E}$ can be estimated from the first cycle of loading (see. Fig. 3) and they are taken as $135 \mathrm{MPa}$ and $126.35 \mathrm{GPa}$, respectively. Variations in viscous stress relaxation with corresponding power law fits, for which constants are determined using Eq (26), can be plotted as shown in Fig. 11. It was found that when $\mathrm{Z}$ is bigger than 3000, the quality of fitting will not be changed significantly. Hence 3000 to 4500 and 2 to 3 are chosen as the ranges for $\mathrm{Z}$ and $\mathrm{n}$, respectively. 
Finally, upper and lower bounds obtained from initial estimates of Chaboche parameters are shown in Table 2 and

Table 3, respectively. Using these initial estimates of parameters and using the optimisation procedure described in the work of Saad et al [1], material parameters for the Chaboche model were obtained for $\mathrm{P} 91$ at $600^{\circ} \mathrm{C}$ for different strain ranges. Optimisation was conducted using LSQNONLIN within MATLAB (the Chaboche model ordinary differential equations (ODEs) were solved using ODE45). The optimisation algorithm attempts to minimise two objective functions; the first one is for the difference between stresses calculated by the Chaboche model and experimental stresses while the second objective is to minimise the error of stress amplitudes $\left(\sigma_{\max }-\sigma_{\min }\right)$ calculated by the Chaboche model. Resultant optimised parameters are tabulated in Table 4.

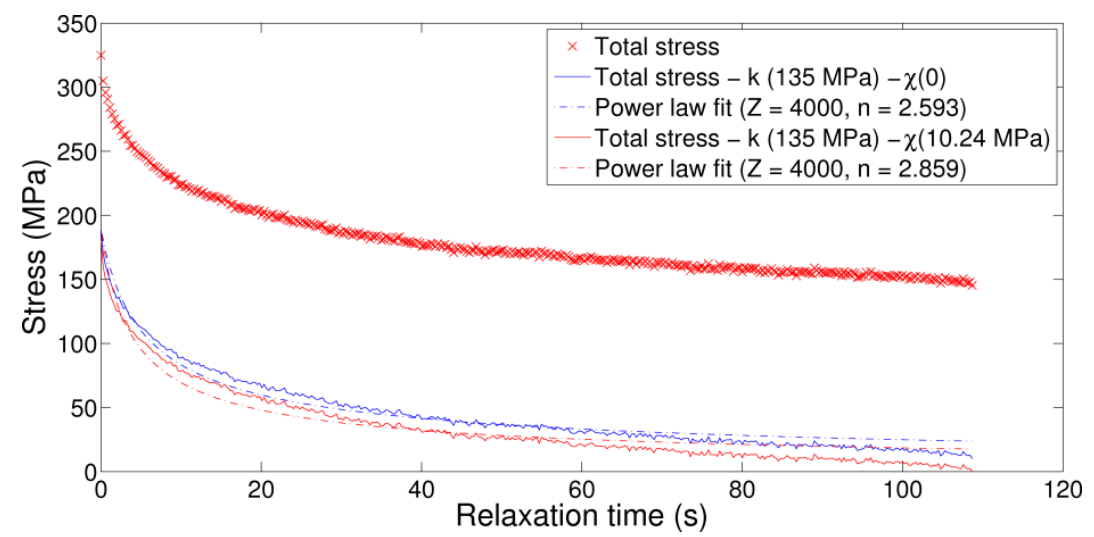

Fig. 11: Total stress relaxation curve, possible viscous stress relaxation curves and corresponding power law fits of first cycle of the dwell test with strain range of $\pm 0.5 \%$

Table 2: Upper bounds for parameters for Chaboche viscoplasticity model at $600^{\circ} \mathrm{C}$ at different strain ranges

\begin{tabular}{cccccccccccc}
\hline $\begin{array}{c}\Delta \varepsilon \\
(\%)\end{array}$ & $\begin{array}{c}\mathrm{a} 1 \\
(\mathrm{MPa})\end{array}$ & $\mathrm{C} 1$ & $\begin{array}{c}\mathrm{a} 2 \\
(\mathrm{MPa})\end{array}$ & $\mathrm{C} 2$ & $\begin{array}{c}\mathrm{Z} \\
\left(\mathrm{MPa} \times \mathrm{s}^{1 / \mathrm{n}}\right)\end{array}$ & $\mathrm{n}$ & $\mathrm{b}$ & $\mathrm{Q}$ & $\mathrm{k}$ & $\mathrm{E}$ & $\mathrm{H}$ \\
\hline \pm 0.2 & 45 & 200684 & 20 & 2000 & 4500 & 3 & 2.836 & -35 & 150.1 & 130 & -1 \\
\pm 0.25 & 45 & 200684 & 20 & 2000 & 4500 & 3 & 2.836 & -50 & 150.1 & 130 & -1.8 \\
\pm 0.4 & 45 & 200684 & 20 & 2000 & 4500 & 3 & 2.836 & -50 & 150.1 & 130 & -1.8
\end{tabular}


Table 3: Lower bounds for parameters for Chaboche viscoplasticity model at $600^{\circ} \mathrm{C}$ at different strain ranges

\begin{tabular}{cccccccccccc}
\hline $\begin{array}{c}\Delta \varepsilon \\
(\%)\end{array}$ & $\begin{array}{c}\mathrm{a} 1 \\
(\mathrm{MPa})\end{array}$ & $\mathrm{C} 1$ & $\begin{array}{c}\mathrm{a} 2 \\
(\mathrm{MPa})\end{array}$ & $\mathrm{C} 2$ & $\mathrm{Z}\left(\mathrm{MPa} \times \mathrm{s}^{1 / \mathrm{n}}\right)$ & $\mathrm{n}$ & $\mathrm{b}$ & $\begin{array}{c}\mathrm{Q} \\
(\mathrm{MPa})\end{array}$ & $\begin{array}{c}\mathrm{k} \\
(\mathrm{MPa})\end{array}$ & $\begin{array}{c}\mathrm{E} \\
(\mathrm{GPa})\end{array}$ & $\mathrm{H}$ \\
\hline 0.2 & 10 & 20 & -50 & 500 & 3000 & 1.9 & 0.9 & -45 & 135 & 120 & -1.8 \\
\pm 0.25 & 10 & 20 & -50 & 500 & 3000 & 1.9 & 0.9 & -65 & 135 & 120 & -2.3 \\
\pm 0.4 & 10 & 20 & -50 & 500 & 3000 & 1.9 & 0.9 & -65 & 135 & 120 & -2.2
\end{tabular}

Table 4: Optimised parameters for Chaboche viscoplasticity model at $600^{\circ} \mathrm{C}$ at different strain ranges

\begin{tabular}{|c|c|c|c|c|c|c|c|c|c|c|c|}
\hline $\begin{array}{l}\Delta \varepsilon \\
(\%)\end{array}$ & $\begin{array}{c}\mathrm{a} 1 \\
(\mathrm{MPa})\end{array}$ & $\mathrm{C} 1$ & $\begin{array}{c}\mathrm{a} 2 \\
(\mathrm{MPa})\end{array}$ & $\mathrm{C} 2$ & $\mathrm{Z}\left(\mathrm{MPa} \times \mathrm{s}^{1 / \mathrm{n}}\right)$ & $\mathrm{n}$ & $\mathrm{b}$ & $\begin{array}{c}\mathrm{Q} \\
(\mathrm{MPa})\end{array}$ & $\begin{array}{c}\mathrm{k} \\
(\mathrm{MPa})\end{array}$ & $\begin{array}{c}\mathrm{E} \\
(\mathrm{GPa})\end{array}$ & $\mathrm{H}$ \\
\hline \pm 0.2 & 42 & 420.03 & 14 & 500 & 4248.7 & 1.9 & 1 & -35 & 135 & 130 & -1.76 \\
\hline \pm 0.25 & 44.2 & 1385 & 18.12 & 1394 & 3000 & 1.9 & 1.97 & -52.25 & 135 & 130 & -2.3 \\
\hline \pm 0.4 & 45 & 620 & 19.95 & 621 & 3000 & 1.9 & 1.73 & -62.14 & 135 & 128.7 & -2.2 \\
\hline
\end{tabular}

\section{Determination of continuum damage model parameters of P91}

\subsection{Determination of damage initiation parameters}

The state of damage can be observed indirectly from changes in effective elastic modulus as shown in Eq (8). With the knowledge of cyclic yield strength $(\mathrm{k}+\mathrm{R})$ from the previous section, a linear region within a cycle of a fatigue test (line BC in Fig. 7) can be obtained and its slope is taken as the effective elastic modulus of a cycle. Fig. 12 shows the evolution of the effective elastic modulus against accumulated plastic strain for the three different strain ranges for $\mathrm{P} 91$ at $600^{\circ} \mathrm{C}$. Scatter in the experimental results is expected due to many reasons. As mentioned in the previous section, finding a linear region BC within a hysteresis loop (see Fig. 7) is challenging and scatter for the slope (E) fitted using data points within the region $\mathrm{BC}$ is expected. Moreover, variation in total strain ranges controlled due to delay in feedback loop signal could cause scatters too. The error of strain range control is poorer for the $0.2 \%$ case which results in more data scatters. 


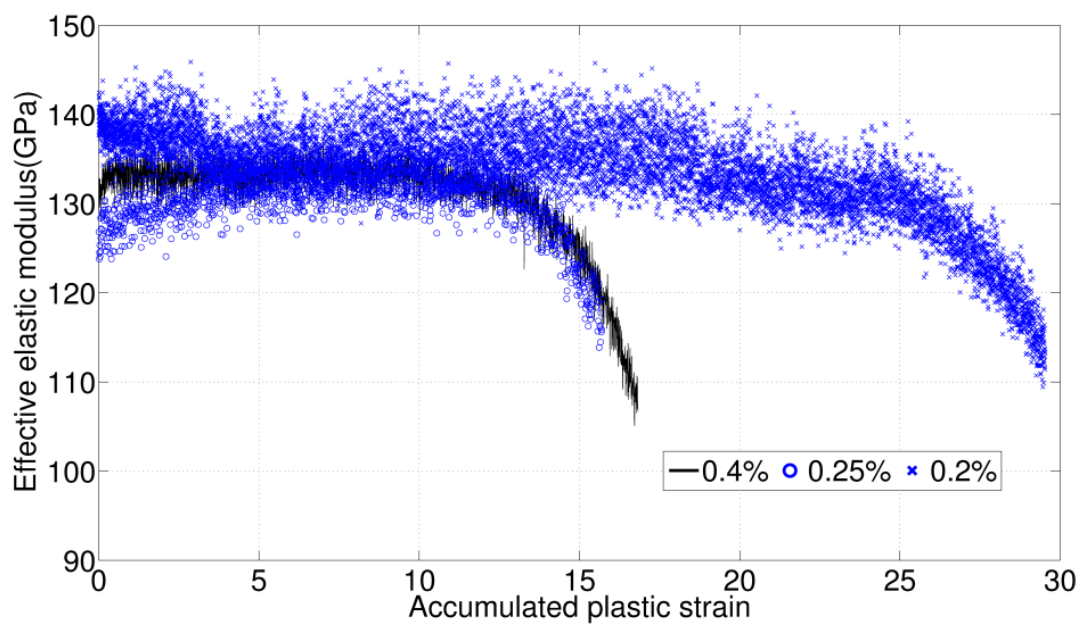

Fig. 12: Effective elastic modulus evolution for $\mathrm{P} 91$ at $600{ }^{\circ} \mathrm{C}$ for $\pm 0.4 \%, \pm 0.25 \%$ and $\pm 0.2 \%$ strain ranges

Fig. 12 can be used to determine the point at which a significant reduction in effective modulus starts to occur. This is taken to be the initiation point of CDM [37]. The accumulated plastic strain at this point is designated plastic strain threshold for damage initiation $\left(p_{D}\right)$. When the material is subject to the plastic strain ranges shown in Fig. 4, its LCF lifetime can be estimated using Manson-Coffin relationship [45] and its mathematical form is shown as:

$$
\frac{\Delta \varepsilon_{\mathrm{p}}}{2}=(2 \mathrm{~N})^{\mathrm{c}} \varepsilon_{\mathrm{f}}^{\prime}
$$

where $\varepsilon_{\mathrm{f}}^{\prime}$ is fatigue ductility coefficient and $\mathrm{c}$ is fatigue ductility exponent. $2 \mathrm{~N}$ is the number of strain reversals. By taking log to both side of Eq (27), the relationship between $2 \mathrm{~N}$ and $\frac{\Delta \varepsilon}{2}$ can be expressed as in Eq (28). This means a linear relationship is expected between log $\left(\frac{\Delta \varepsilon_{\mathrm{p}}}{2}\right)$ and $\log (2 \mathrm{~N})$

$$
\log \left(\frac{\Delta \varepsilon_{\mathrm{p}}}{2}\right)=\operatorname{cog}(2 \mathrm{~N})+\log \left(\varepsilon_{\mathrm{f}}^{\prime}\right)
$$


To observe this LCF Manson-Coffin relationship for the experimental LCF tests used for the current work, $\log (2 \mathrm{~N})$ at the point $p_{D}$ are plotted against $\log \left(\frac{\Delta \varepsilon_{\mathrm{p}}}{2}\right)$ as shown in Fig. 13 (refer to Fig. 4 for $\Delta \varepsilon_{\mathrm{p}}$ values). The numbers of reversals at failure point are also included in Fig. 13. In contrary to LCF Manson-Coffin theory, a non-linear relationship is observed for both damage initiation and failure life. This indicates future data requirement for LCF tests, with strain range higher than $\pm 0.4 \%$ and lower than $\pm 0.2 \%$, to observe the LCF region and to obtain transition point from LCF to high cycle fatigue (HCF).

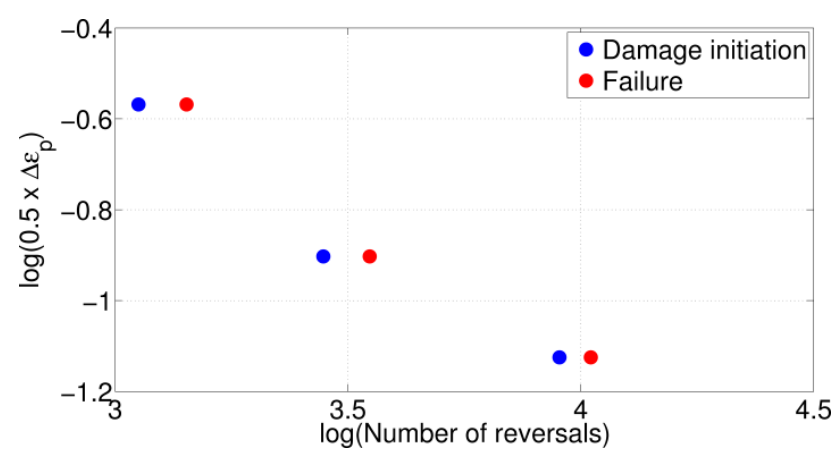

Fig. 13: Number of reversals $(2 \mathrm{~N})$ at $\mathrm{p}_{\mathrm{D}}$ and at failure $\left(2 \mathrm{~N}_{\mathrm{f}}\right)$.

For all cases, the cycle at which damage initiates is between $70-80 \%$ of failure cycle $\left(N_{f}\right)$ (see Fig. 13). It is important to be able to predict this point if the model developed here is to be used in analytical applications. Although Manson-Coffin method can be used to estimate the number of cycle to $p_{D}$, the method only applies to strain controlled problems with a constant strain range. To generalise damage initiation approach for different loading types, a stored energy accumulation method [36] will be applied here. It is based on the hypothesis that the stored energy $\left(\omega_{\mathrm{s}}\right)$ which is the result of microstress concentration developing near dislocation networks can be used to estimate damage initiation. It can be shown [37] that the stored energy per unit volume for a uniaxial fatigue problem with completely reversed loading can be expressed as:

$$
\mathrm{w}_{\mathrm{S}}=\int_{0}^{\mathrm{t}} \mathrm{R} \dot{\mathrm{p}}+\chi \dot{\mathrm{p}} \mathrm{dt}
$$


For a completely reversed loading, Lemaitre and Chaboche [46] have metioned that energy related to kinematic hardening will be dissipated as heat during the unloading cycle. Hence, only the energy related to the isotropic softening is stored within the system and Eq (29) can be simplified to:

$$
\mathrm{w}_{\mathrm{S}}=\int_{0}^{\mathrm{t}(\text { damage initiation })} \mathrm{R} \dot{\mathrm{p}} \mathrm{dt}=\int_{0}^{\mathrm{p}_{\mathrm{D}}} \mathrm{R} \mathrm{dp}
$$

For the simplest case where the material becomes perfectly plastic within a short period of time (i.e. stress amplitude is unchanged), the stored energy can be estimated using Eq (31).

$$
\mathrm{w}_{\mathrm{S}}=\mathrm{R}_{\infty} \mathrm{pD}
$$

where plastic strain threshold $\left(\mathrm{p}_{\mathrm{D}}\right)$ is the accumulated plastic strain at the point where damage initiation occurs and $R_{\infty}$ is the stabilised value of $R$.

To calculate damage initiation energy, it is necessary to know plastic strain thresholds. These may then be estimated from experimental elastic modulus evolution plots (see Fig. 12). The damage initiation point is the point where the effective modulus reduction begins. Values for the $\pm 0.2 \%, \pm 0.25 \%$ and $\pm 0.4 \%$ test were found to be approximately 24.81 at $9000^{\text {th }}$ cycle, 12.9 at $2800^{\text {th }}$ cycle and 11.94 at $1123^{\text {rd }}$ cycles, respectively. Fig. 14 plots $\mathrm{R}$ against $\mathrm{p}$ for the three different strain ranges before damage initiation. It can be seen that $\mathrm{R}$ is not stabilised and linear softening can be observed until the point of damage initiation. Finally, using the estimated plastic strain thresholds and R (shown in Fig. 14), the accumulated energy at damage initiation (or energy threshold) can be estimated using Eq (30) The energy values are tabulated in Table 5. For $0.25 \%$ and $0.4 \%$ cases, damage initiation energies are within $\pm 3 \%$ however $0.2 \%$ case give energy value around 1.6 times higher than the other cases. An average energy among the three cases is taken as the energy for damage initiation for the current case although more data is required to obtain the trend of energy stored related to the applied strain range. 


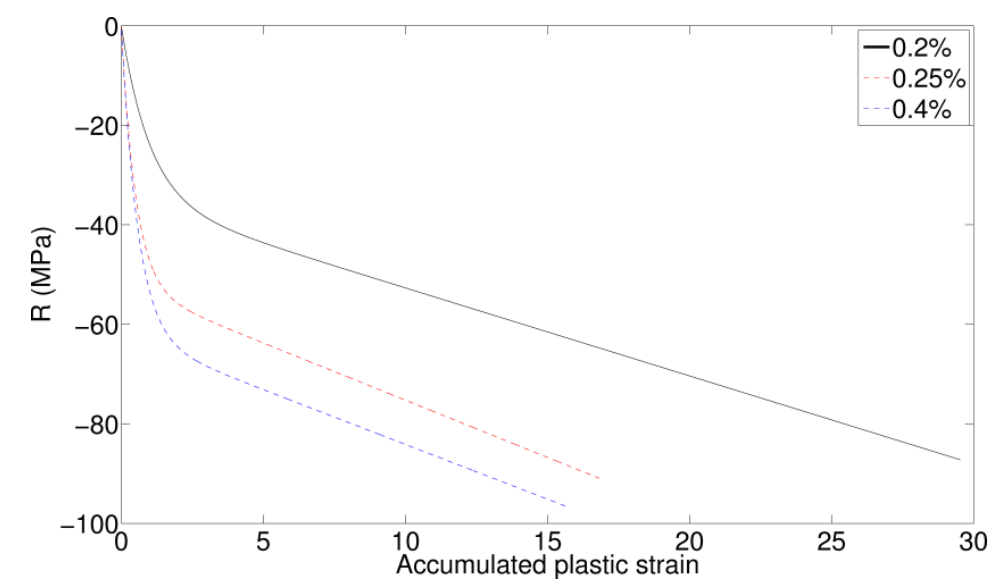

Fig. 14: Stress amplitude changes of $P 91$ at $600^{\circ} \mathrm{C}$ for $\pm 0.4 \%, \pm 0.25 \%$ and $\pm 0.2 \%$ strain ranges.

Table 5: Thresholds of plastic strain and accumulated stored energy for damage initiation of $\mathrm{P91}$ at $600^{\circ} \mathrm{C}$ for $\pm 0.4 \%, \pm 0.25 \%$ and $\pm 0.2 \%$ strain ranges

\begin{tabular}{ccc}
\hline Strain range & Plastic strain threshold $\left(\mathrm{p}_{\mathrm{D}}\right)$ & $\begin{array}{c}\text { Accumulated energy threshold } \\
\left(\mathrm{MJ} / \mathrm{m}^{3}\right)\end{array}$ \\
\hline $0.2 \%$ & 24.81 & 1377 \\
$0.25 \%$ & 12.9 & 839 \\
$0.4 \%$ & 11.94 & 863
\end{tabular}

\subsection{Determination of damage evolution parameters}

Isotropic damage variable, $\mathrm{D}$, can be defined by rearranging $\mathrm{Eq}$ (8) (see Eq (32)). The evolution of this damage parameter is plotted for the P91 experiments against accumulated plastic strain in Fig. 15. It may be observed that the rate of damage accumulation for the $\pm 0.2 \%$ case is much smaller than other experiments. Despite the modest reduction in the strain range between the $\pm 0.25 \%$ and $\pm 0.2 \%$ tests, significant differences in saturated plastic strain range $(0.25 \%$ and $0.15 \%$, respectively) and in the number of cycles to failure (3522 and 10512 cycles, respectively) are observed. This observation may be verified through inspection of Fig. 4 and Fig. 5. It is reasoned here that the $\pm 0.2 \%$ test is at the borderline between LCF and high cycle fatigue (HCF) mechanisms. Nevertheless, more experiments with different strain ranges is required to solidify this assumption. 


$$
D=1-\frac{\tilde{E}}{E}
$$

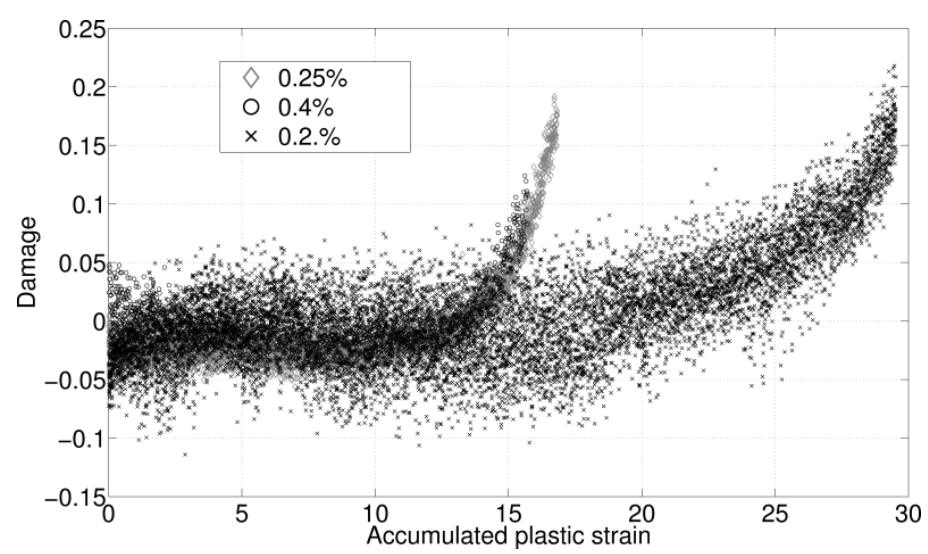

Fig. 15: Damage against accumulated plastic strain of $\mathrm{P91}$ at $600{ }^{\circ} \mathrm{C}$ for $\pm 0.4 \%, \pm 0.25 \%$ and $\pm 0.2 \%$ strain ranges.

Lemaitre and Chaboche [35] have proven thermodynamically that the isotropic damage evolution rate under isothermal conditions can be expressed in terms of accumulated plastic strain by Eq (33).

$$
\dot{\mathrm{D}}=\left(\frac{\mathrm{Y}}{\mathrm{S}}\right)^{\mathrm{S}} \dot{\mathrm{p}} \mathrm{H}(\mathrm{p}-\mathrm{pD})
$$

A Heaviside step function is used to ensure that damage only accumulates after the threshold point $p_{D}$ has been exceeded $\left(\mathrm{H}(\mathrm{p}-\mathrm{pD})\right.$ takes a value of 1 if $\mathrm{p}$ is greater than or equal to $p_{D}$ and is zero at all other times). $\mathrm{S}$ and $\mathrm{s}$ are temperature dependent material parameters. For the current case, linear evolution of damage is assumed and hence $\mathrm{s}=1$. $\mathrm{Y}$ is thermodynamic conjugate of damage $\mathrm{D}$ and it can be expressed as:

$$
Y=\frac{\tilde{\sigma}^{2} R_{v}}{2 E}
$$

where $R_{v}$ is a triaxiality ratio (which accounts for the loading dependence of damage for multiaxial loading cases) and is defined by Eq (35). For uniaxial loading cases, it may be shown that $R_{v}=1$. 


$$
\mathrm{R}_{\mathrm{V}}=\frac{2}{3}(1+v)+3(1-2 v)\left(\frac{\sigma_{\mathrm{H}}}{\sigma_{\mathrm{eq}}}\right)^{2}
$$

$\sigma_{\mathrm{H}}$ is the hydrostatic stress and $\sigma_{\mathrm{eq}}$ is equivalent stress (most commonly defined as the von Mises stress).

Only S remains to be defined in Eq (33). S may be expressed using Eq (36) (which is found using Eqs (33) to (35)). $\frac{\mathrm{dD}}{\mathrm{dp}}$ may be found from a plot of damage evolution against accumulated plastic strain between $\mathrm{p}_{\mathrm{D}}$ and failure (see. Fig. 15). For the present work, an $\mathrm{S}$ value of approximately 3.7297 is taken by averaging data from three different strain ranges.

$$
S=\frac{\tilde{\sigma}^{2}}{2 E(1-D)^{2} \frac{d D}{d p}}
$$

\section{Results and discussion}

\subsection{Uniaxial LCF behaviour of P91 using determined constants for Chaboche viscoplasticity model}

The accuracy of simulated hysteresis loops using the Chaboche parameters listed in Table 4 are tested against the experimental results for cycles at the beginning of each of the tests and at a cycle at which the isotropic hardening is stabilised. Fig. 16, Fig. 18 and Fig. 20 show the comparisons of hysteresis loops for $0.4 \%, 0.25 \%$ and $0.2 \%$ cases, respectively. The evolution of stress amplitude was also compared for each test in Fig. 17, Fig. 19 and Fig. 21. The coefficient of determination values $\left(\mathrm{R}^{2}\right)$ are also shown to illustrate the quality of fittings. Generally $\mathrm{R}^{2}$ value is greater than 0.9 . This shows that estimated hysteresis loops using material parameters from Table 4 can fit experimental loops well.

Due to large value of kinematic constants (C1 and $\mathrm{C} 2$ ) shown in Table 4, the change in kinematic stress is less than $6 \mathrm{MPa}$ or it becomes insignificant after $13 \%$ of failure lifetime and the isotropic softening is the main cause for changes in the stress amplitude throughout the lifetime. Hence, it is concluded that the isotropic constants are representative of the material under the quasi-static isothermal conditions. However during the first few cycles, as 
shown in Fig. 16, Fig. 18 and Fig. 20, kinematic hardening constants seem to underestimate the hardening back stresses (particularly for $\pm 0.2 \%$ case). Stress amplitudes for the $\pm 0.2 \%$ case are underestimated by around $15 \mathrm{MPa}$ during the first few cycles as shown in Fig. 21 . Apart from these first few cycles, the model has predicted stresses within $\pm 10 \mathrm{MPa}$.

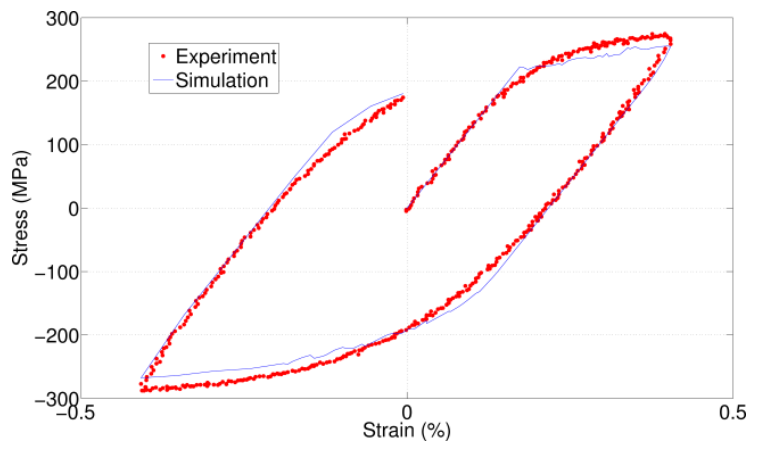

(i)

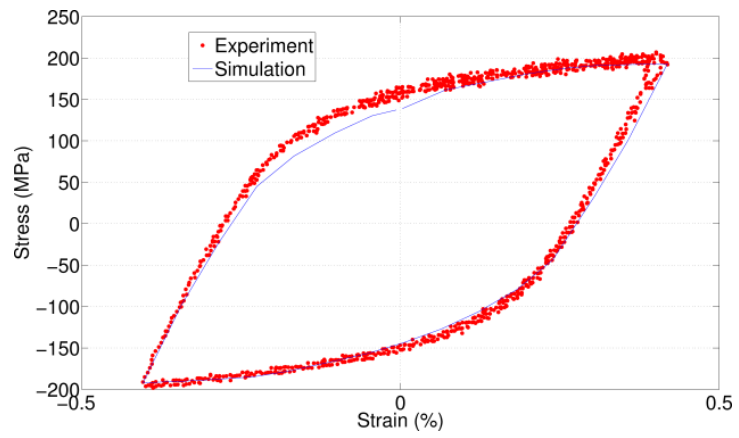

(ii)

Fig. 16: Stress-strain behaviour of $P 91$ at $600^{\circ} \mathrm{C}$ at $\pm 0.4 \%$ strain range (i) for first cycle $\left(R^{2}=0.996\right)$ (ii) for $800^{\text {th }}$ cycle $\left(\mathrm{R}^{2}=0.996\right)$.

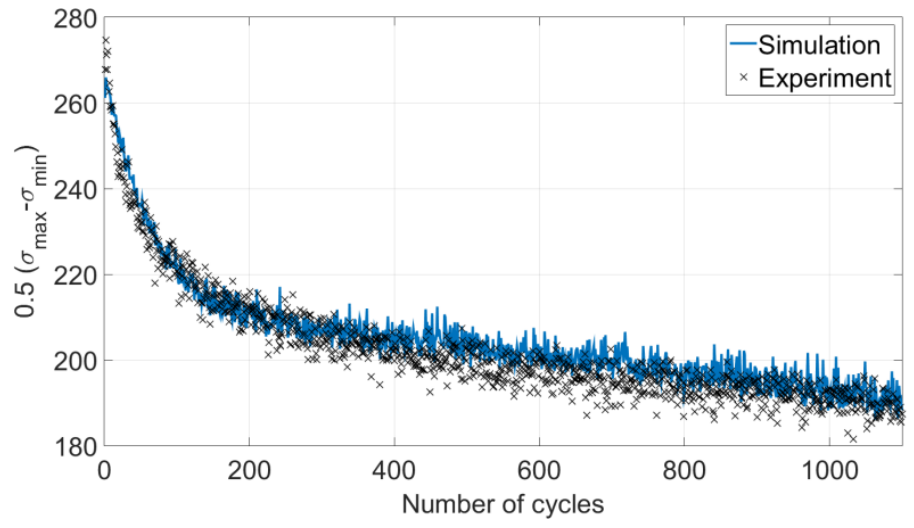

Fig. 17: Evolution of stress amplitude of $\mathrm{P91}$ at $600^{\circ} \mathrm{C}$ at $\pm 0.4 \%$ strain range $\left(\mathrm{R}^{2}=0.925\right)$.

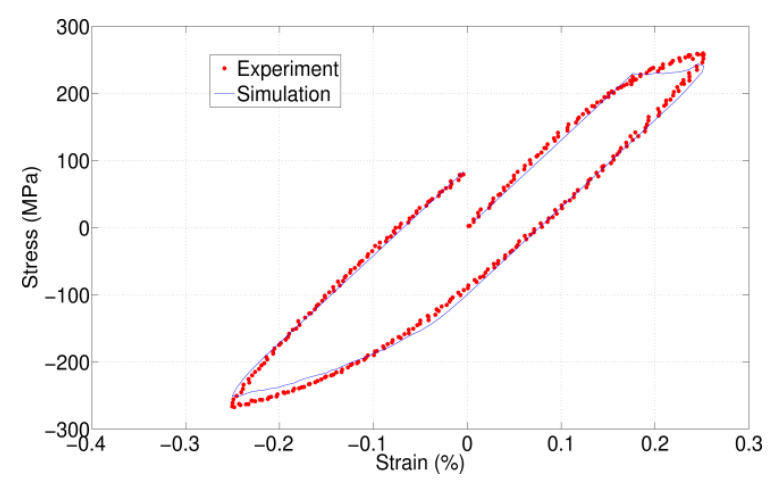

(i)

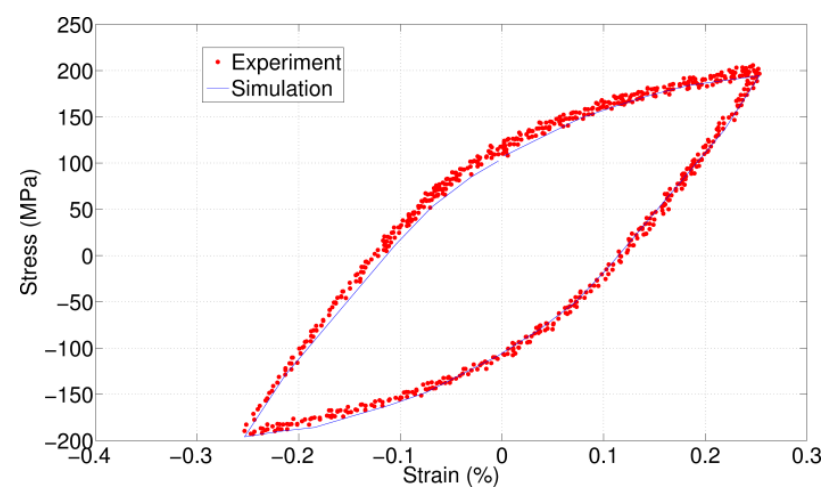

(ii)

Fig. 18: Stress-strain behaviour of $\mathrm{P} 91$ at $600^{\circ} \mathrm{C}$ at $\pm 0.25 \%$ strain range (i) for first cycle $\left(\mathrm{R}^{2}=0.998\right)$ (ii) for 2000th cycle $\left(R^{2}=0.999\right)$. 


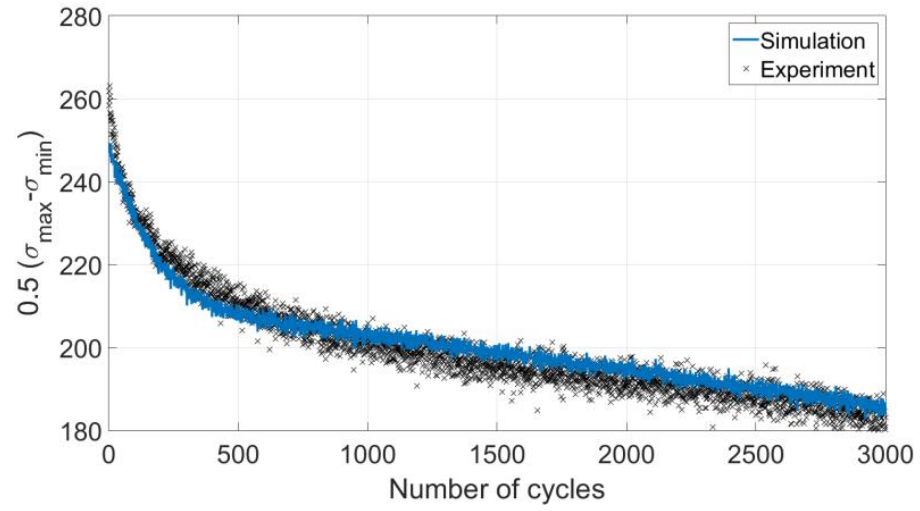

Fig. 19: Evolution of stress amplitude of $P 91$ at $600^{\circ} \mathrm{C}$ at $\pm 0.25 \%$ strain range $\left(R^{2}=0.956\right)$.

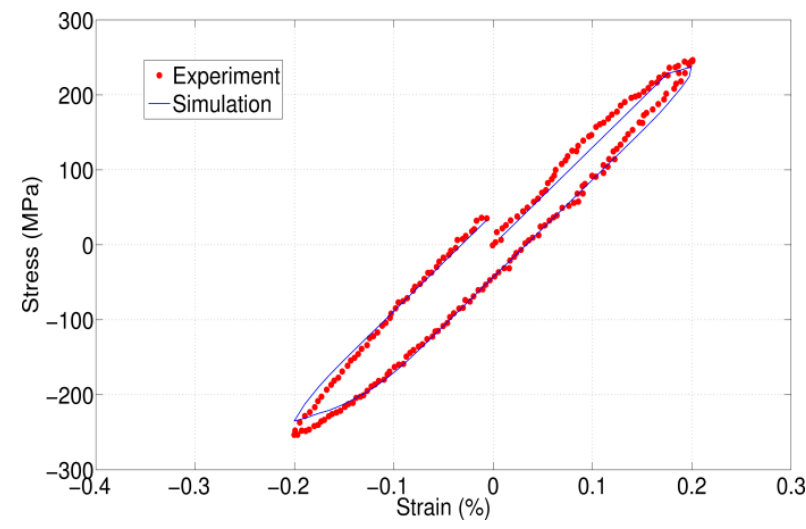

(i)

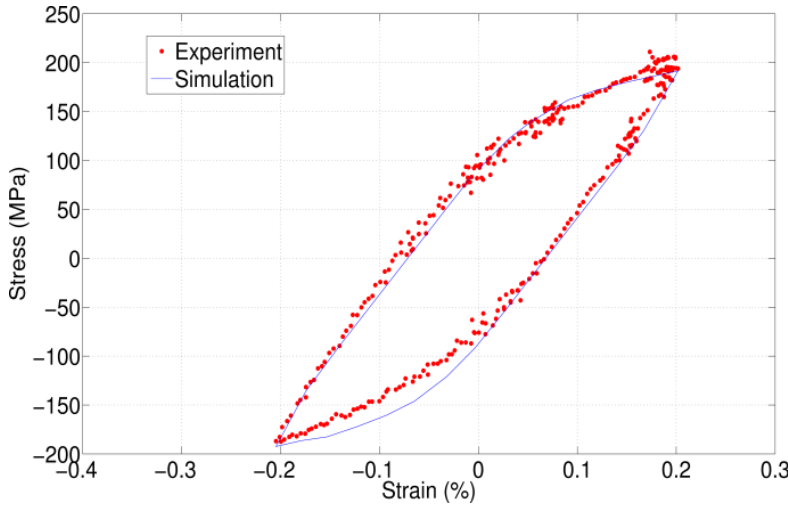

(ii)

Fig. 20: Stress-strain behaviour of $P 91$ at $600^{\circ} \mathrm{C}$ at $\pm 0.2 \%$ strain range (i) for first cycle $\left(R^{2}=0.998\right)$ (ii) for $6000^{\text {th }}$ cycle $\left(R^{2}=0.996\right)$.

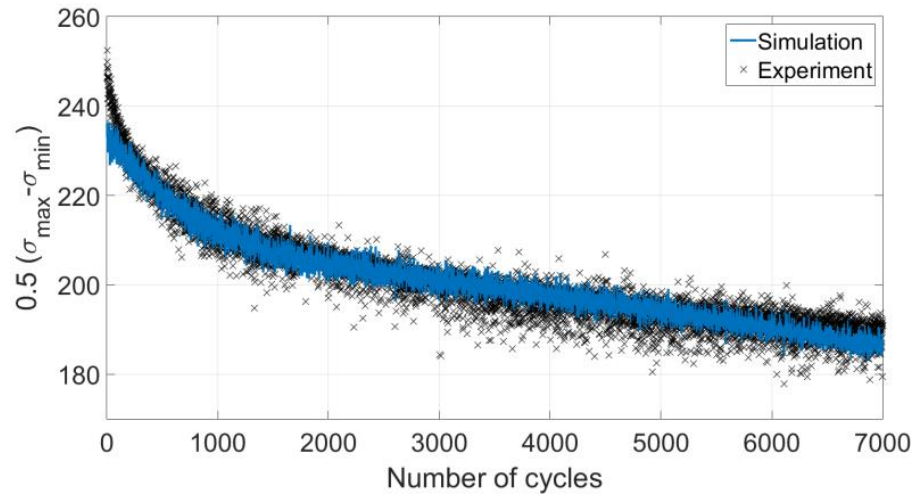

Fig. 21: Evolution of stress amplitude of $P 91$ at $600^{\circ} \mathrm{C}$ at $\pm 0.2 \%$ strain range $\left(R^{2}=0.907\right)$. 


\subsection{Uniaxial LCF behaviour and fatigue lifetime of P91 using determined constants for}

\section{Chaboche viscoplasticity-damage model}

The Chaboche model can be used to model cyclic plasticity effects on the material behaviour of P91. However, the fully coupled damage model is necessary to model further stress drop after cyclic plasticity is stabilised and to estimate fatigue lifetime $\left(N_{f}\right)$ of P91. The coupled damage model is applied to the study of P91 during fully reversed with $\pm 0.4 \%, \pm 0.25 \%$ and $\pm 0.2 \%$ strain controlled LCF loads at $600^{\circ} \mathrm{C}$. Damage initiates within the model when the accumulated plastic strain is higher than $\mathrm{p}_{\mathrm{D}}$ at the average energy obtained from Table 5 . 3.7297 is used for average damage evolution parameter S. Afterwards, stress amplitude evolutions are compared against experimental results. Damage initiation points for $\pm 0.4 \%$ $\pm 0.25 \%$ cases are predicted within $\pm 8 \%$ by the proposed coupled damage model as shown in Fig. 22 and Fig. 23, respectively. Damage initiates after 1200 cycles and 3000 cycles, respectively, for $\pm 0.4 \%$ and $\pm 0.25 \%$ cases as opposed to experimental lifetimes of 1123 cycles and 2800 cycles. However for the $\pm 0.2 \%$ case, damage initiates at 6800 cycles as opposed to 9000 cycles (see.Fig. 24) given by experiment. Moreover, damage evolution rate or rate of stress drop for $\pm 0.2 \%$ case is also predicted to be much faster than experimental rate.

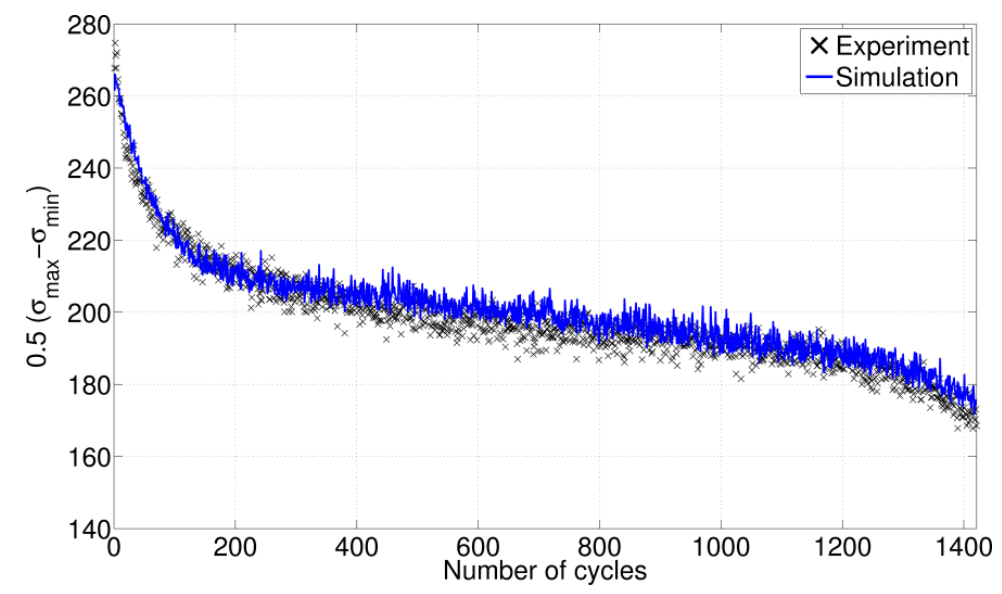

Fig. 22: Stress amplitude as given by experiments and by Chaboche model coupled with damage simulation for $\mathrm{P} 91$ at $600^{\circ} \mathrm{C}$ with $\pm 0.4 \%$ strain range. 


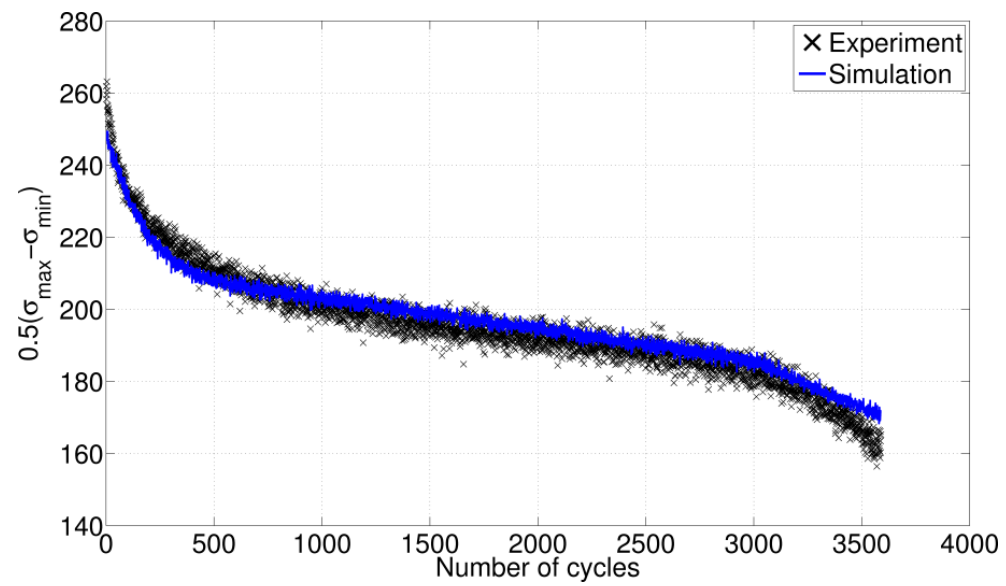

Fig. 23: Stress amplitude as given by experiments and by Chaboche model coupled with damage simulation for $\mathrm{P} 91$ at $600^{\circ} \mathrm{C}$ with $\pm 0.25 \%$ strain range.

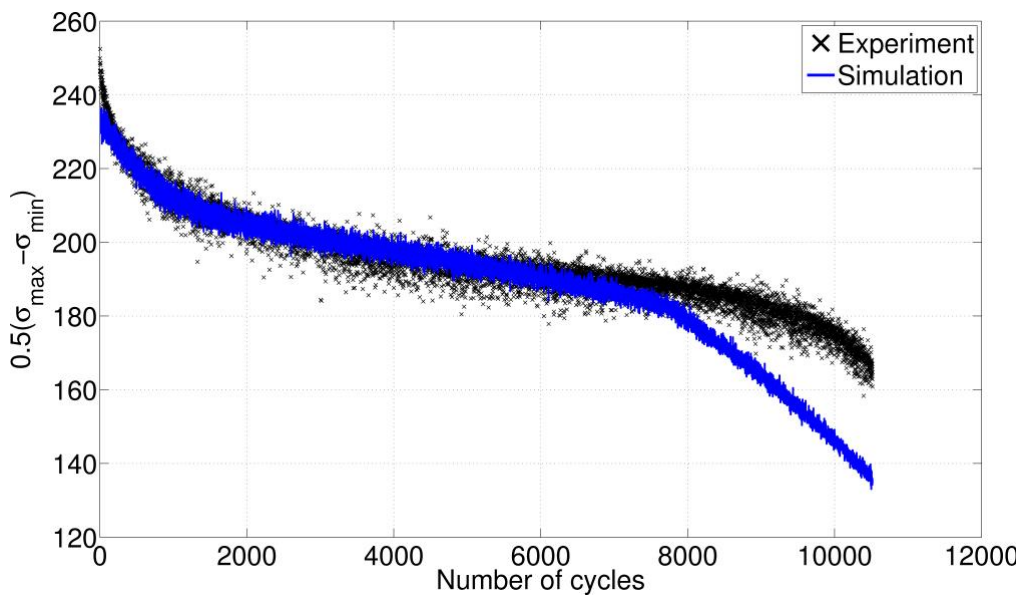

Fig. 24: Stress amplitude as given by experiments and by Chaboche model coupled with damage simulation for $\mathrm{P} 91$ at $600^{\circ} \mathrm{C}$ with $\pm 0.2 \%$ strain range.

Finally, failure lifetimes for three different cases are compared against experimental failure lifetimes. $10 \%$ stress drop method as shown in Fig. 6 is used to evaluate the failure lifetime. The failure lifetimes for $\pm 0.4 \%, \pm 0.25 \%$ and $\pm 0.2 \%$ cases are 1600,4250 and 9500 cycles respectively. Experimental lifetimes for $\pm 0.4 \%, \pm 0.25 \%$ and $\pm 0.2 \%$ cases are 1424,3522 and 10512 cycles respectively. To compare low cycle Manson-Coffin fit between estimated and experimental lifetimes, $\log (2 \mathrm{~N})$ vs $\log \left(0.5 \times \Delta \varepsilon_{\mathrm{p}}\right)$ is plotted as shown in Fig. 25. It can be seen that a better linear fit can be obtained from the set of estimated lifetimes. This indicates that if identical damage initiation energy and damage evolution rate are applied to LCF simulation with different applied strain ranges, the lifetime estimated will follow the MasonCoffin relationship. Among the three cases with different strain ranges, only the $\pm 0.2 \%$ case gives damage initiation energy much higher than the other cases (damage initiation energies 
for $\pm 0.4 \%$ and $\pm 0.25 \%$ cases are within $3 \%$ ). A longer time needed for damage initiation for $\pm 0.2 \%$ indicates that HCF damage could be more dominant for the case.

It needs to be pointed out that the trend and interpretations of fatigue lifetimes are based on only three isothermal loading cases with different loading amplitudes. Therefore, variabilities in results could occur since data scatters are expected if more test cases are included in the plot of lifetime (Fig. 25). Additionally, it is necessary to repeat test cases at the same loading amplitude in the future in order to obtain error bars for experimental lifetime.

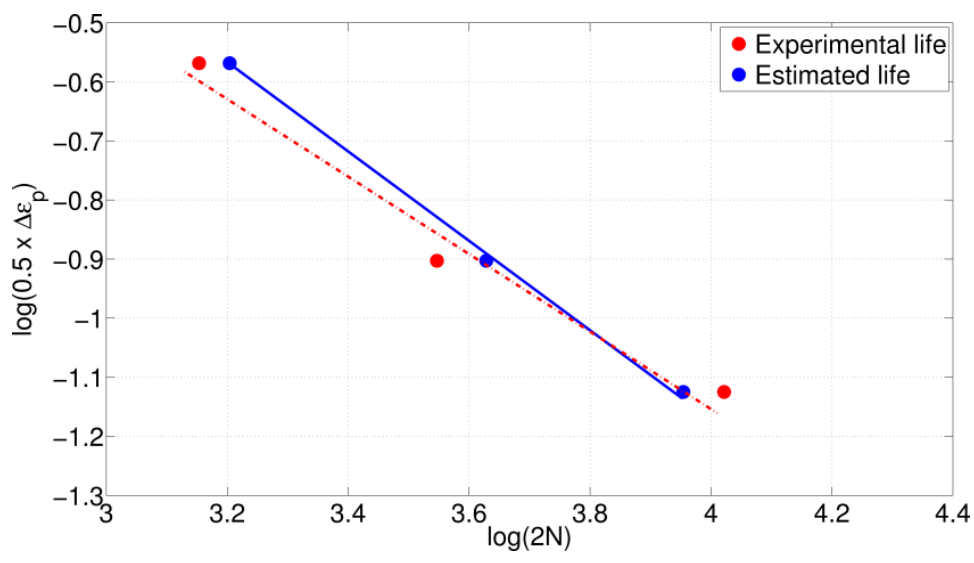

Fig. 25: Comparison of number of reversals as predicted by a damage model to experimental failure life

\section{Conclusions and future work}

Previous work on the simulation of cyclic plasticity of P91 under isothermal uniaxial fatigue loading using the Chaboche viscoplasticity model has been extended to take account of stress drop due to damage from the formation and the evolution of microstructural defects. Cottrell's stress partition method has been used to make initial estimates of the material parameters for the Chaboche model. These initial estimates have then been optimised using experimental hysteresis data for $\mathrm{P} 91$ at $600^{\circ} \mathrm{C}$ with three different strain ranges. Optimised sets of Chaboche material parameters have been used to calculate the stress-strain response of P91 for different strain ranges. Apart from the first few cycles, stresses are predicted within $\pm 10 \mathrm{MPa}$.

To model the effects of microstructural defects on the macroscopic stress-strain response of P91, an isotropic damage evolution model is coupled with the Chaboche cyclic plasticity model. Although the Manson-Coffin fit can be used to estimate the initiation of damage, it 
only works for limited strain controlled tests with constant strain amplitude. Alternatively, the initiation of damage is estimated based on accumulated stored energy. Both energy for damage initiation and rate of evolution of damage were significantly reduced for the $\pm 0.2 \%$ strain range test compared to the $\pm 0.25 \%$ and $\pm 0.4 \%$ tests. The latter have similar range of damage initiation energy and damage evolution rate. The relatively large number of cycles to failure and low plastic strain range suggest that HCF damage mechanisms could be dominant in the $\pm 0.2 \%$ case. However, more experimental data using strain ranges higher than $\pm 0.4 \%$ is needed in future to validate this hypothesis. Using average damage initiation energy and damage evolution parameters, the stress-strain responses for P91 are predicted until the point of failure by $10 \%$ stress drop criterion. Predicted lifetimes are within $20 \%$ of the experimental lifetime. A linear Manson-Coffin fit is not obtained from experimental LCF test. On the other hand, a linear fit can be observed from the estimated lifetimes of LCF cases with identical damage initiation energy.

The model presented in this paper can be applied to power plant materials like P91 under LCF loads at the constant temperature since both the Chaboche cyclic hardening and damage parameters are independent of load amplitude. Although only uniaxial fatigue is considered in the current study, uniaxial stresses and strains can be substituted by a scalar equivalent stress (von Mises) and scalar equivalent strain for three-dimensional problems. Further work is required to estimate the stored energy for damage initiation with strain ranges between $\pm 0.4 \%$ and $\pm 0.2 \%$ to extract the transition point from LCF failure to HCF failure and to investigate the variabilities in data for experimental lifetime. Studies on temperature dependency of the Chaboche and damage parameters are under way to extend the model for anisothermal and multiaxial fatigue problems. Additional microstructural studies are also required to quantitatively define the mechanisms responsible for different types of strain hardening/softening effects and damage at different stages of lifetime.

\section{Acknowledgement}

We would like to acknowledge the support of the Engineering and Physical Research Council (EPSRC) for their support for the project - Flexible and Efficient Power Plant: Flex-E-Plant (Grant number: EP/K021095/1). We also thank the following partners for their the valuable contributions: Alstom Power Limited, Doosan Babcock Limited, Centrica plc., EDF Energy 
(West Burton Power) Limited, E.ON Technologies (Ratcliffe) Limited, Goodwin Steel

Castings Limited, NPL Management Limited, R-MC Power Recovery Limited, RWE

Generation UK plc., Scottish and Southern Energy (SSE) plc., Siemens Industrial

Turbomachinery and TWI Limited.

\section{References}

1. Saad, A.A., et al., Characterization of viscoplasticity behaviour of P91 and P92 power plant steels. International Journal of Pressure Vessels and Piping, 2013. 111-112: p. 246-252.

2. Barrett, R.A., P.E. O’Donoghue, and S.B. Leen, An improved unified viscoplastic constitutive model for strain-rate sensitivity in high temperature fatigue. International Journal of Fatigue, 2013. 48: p. 192-204.

3. Koo, G.-H. and J.-H. Kwon, Identification of inelastic material parameters for modified 9Cr-1Mo steel applicable to the plastic and viscoplastic constitutive equations. International Journal of Pressure Vessels and Piping, 2011. 88(1): p. 26-33.

4. $\quad$ Gong, Y.P., et al., Determination of material properties in the chaboche unified viscoplasticity model. Proceedings of the Institution of Mechanical Engineers, Part L: Journal of Materials: Design and Applications, 2010. 224: p. 19-29.

5. Tong, J., Z.L. Zhan, and B. Vermeulen, Modelling of cyclic plasticity and viscoplasticity of a nickelbased alloy using Chaboche constitutive equations. International Journal of Fatigue, 2004. 26(8): p. 829-837.

6. Tobias, H. and L. Jurgen, Identification of Material Parameters for InelasticConstitutive Models Using Stochastic Methods. GAMM-Mitt., 2007. 30(No. 2): p. 409 - 429

7. Ennis, P.J. and A. Czyrska-Filemonowicz, Recent advances in creep-resistant steels for power plant applications. Sadhana Academy Proceedings in Engineering Sciences 28 (3-4), 2003: p. 709-730.

8. Swindeman, R.W., et al., Issues in replacing Cr-Mo steels and stainless steels with $9 \mathrm{Cr}-1 \mathrm{Mo}-\mathrm{V}$ steel. Pressure Vessels Piping 2004. 81: p. 507-512.

9. Gieseke, B.G., C.R. Brinkman, and P J Maziasz, The influence of thermal aging on the microstructure and fatigue properties of modified 9Cr-1Mo steel. Microstruct. Mech. Properties Aging Mater. , 1993.

10. Beatt, R.J.I., et al., Two-Shift Operation of 500 MW Boiler/Turbine Generating Units. Proceedings of the Institution of Mechanical Engineers, Part A: Journal of Power and Energy November, 1983journal. vol. 197 (no. 4): p. 247-255.

11. Prager, N., The Theory of Plasticity: A Survey of Recent Achievements. . Proceedings of the Institute of Mechanical Engineers., 1955. 169: p. 41-57.

12. Ziegler, H., A Modification of Prager's Hardening Rule. . Quarterly of Applied Mathematics. , 1959. 17: p. 55-65.

13. Dafalias, Y.F. and E.P. Popov, Plastic Internal Variables Formalism of Cyclic Plasticity. Journal of Applied Mechanics. , 1976. 43: p. 645-651.

14. Bodner, S.R. and Y. Partom, Constitutive Equations for Elastic-Viscoplastic StrainHardeningMaterials. Journal of Applied Mechanics 1975. 42: p. 385-389.

15. Krempl, E., J.J. McMahon, and D. Yao, Viscoplasticity Based on Overstress with a DifferentialGrowth Law for the Equilibrium Stress. Mechanics of Materials, 1986. 5: p. 35-48

16. Chaboche, J.L., Unified cyclic viscoplastic constitutive equations. Development, capabilities and thermodynamic framework. In: Krausz AS, Krausz K, editors. Unified constitutive laws of plastic deformation. San Diego, USA: Academic Press, 1996. 
17. Hyde, C., W. Sun, and S.B. Leen, Cyclic thermo-mechanical material modelling and testing of 316 stainless steel. International Journal of Pressure Vessels and Piping, 2010. 87: p. 365-372.

18. Zhang, Z., D. Delagnes, and G. Bernhart, Anisothermal cyclic plasticity modelling of martensitic steels. International Journal of Fatigue, 2002. 24(6): p. 635-648.

19. Bernhart, G., et al., High temperature low cycle fatigue behaviour of a martensitic forging tool steel. . International Journal of Fatigue 1999. 21((2)): p. 179-86.

20. Fournier, B., et al., Analysis of the hysteresis loops of a martensitic steel: Part I: Study of the influence of strain amplitude and temperature under pure fatigue loadings using an enhanced stress partitioning method. Materials Science and Engineering: A, 2006. 437(2): p. 183-196.

21. Taira, S., Lifetime of structures subjected to varying load and temperature. Creep Struct., N. J. Hoff Ed. Academic Press, 1952.

22. Wang, W., P. Buhl, and A. Klenk, A unified viscoplastic constitutive model with damage for multiaxial creep-fatigue loading. International Journal of Damage Mechanics, 2015. Vol. 24(3): p. 363-382.

23. Zhang, G., et al., Creep-fatigue interaction damage modelanditsapplicationinmodified 9 Cr-1Mo steel. NuclearEngDes, 2011. 241(12): p. 4856-61.

24. Lu, J., et al., Simulation of the fatigue behaviour of a power plant steel with a damage variable. International Journal of Mechanical Sciences, 2015. 100: p. 145-157.

25. Chaboche, J.L. and F. Gallerneau, Anoverviewofthedamageapproachofdurability modelling atelevatedtemperature. FatigueFractEngMaterStruct, 2001. 24((6)): p. 405-18.

26. Kachanov, L.M., On rupture time under condition of creep. IzvAkadNaukUSSR, Otd. TechnNaukMoskwa, 1958. 8: p. 26-31.

27. Chaboche, J.L., Continuum damage mechanics: PartI - general concepts. J Appl Mech, 1988. 55((1)): p. 59-64.

28. Vaz, M., E.A. de Souza Neto, and P.A. Muñoz-Rojas, Materials Modeling - Challenges and Perspectives, in Advanced Computational Materials Modeling. 2010, Wiley-VCH Verlag GmbH \& Co. KGaA. p. 1-22.

29. Bažant, Z., Why Continuum Damage is Nonlocal: Micromechanics Arguments. J. Eng. Mech., 1991. 10.1061/(ASCE)0733-9399(117:5(1070)): p. 1070-1087.

30. Germain, P., Q. Nguyen, and P. Suquet, Continuum thermodynamics. ASME Journal of Applied Mechanics, 1983. 50: p. 1010-1020.

31. G Pijaudier-Cabot, G. and Z. Bažant, Nonlocal Damage Theory. J. Eng. Mech, 1987. 10(1061): p. 1512-1533.

32. Advani, S.G. and G.W. Laird, Opportunities and challenges of multiscale modeling and simulation in polymer composite processing. International Journal of Material Forming, 2009. 2(1): p. 39-44.

33. Pablo, J.J.d. and W.A. Curtin, Multiscale Modeling in Advanced Materials Research: Challenges, Novel Methods, and Emerging Applications. MRS Bulletin, 2007. 32(11): p. 905-911.

34. Karabasov, S., et al., Multiscale modelling: approaches and challenges. Philosophical Transactions of the Royal Society of London A: Mathematical, Physical and Engineering Sciences, 2014. 372(2021).

35. Lemaitre, J. and J.L. Chaboche, Mechanics of Solid Materials. Cambridge University Press, , 1994.

36. Lemaitre, J. and R. Desmorat, Engineering Damage Mechanics: Ductile, Creep, Fatigue and Brittle Failures. Springer, 2005.

37. Lemaitre, J., A Course on Damage Mechanics (Second Edition). Springer, 1996.

38. Chaboche, J.L., A review of some plasticity and viscoplasticity constitutive theories. International Journal of Plasticity, 2008. 24(10): p. 1642-1693.

39. A.A.Saad, Cyclic plasticity and creep of power plant materials. PhD thesis. University of Nottingham., 2012. 
40. B.Fournier, et al., Comparison of various 9-12\% Cr steels under fatigue and creep-fatigue loadings at high temperature. Materials Science and Engineering: A, 2011. 528(22-23): p. p. 6934-6945.

41. P.F.Giroux, Experimental study and simulation of cyclic softening of tempered martensite ferritic steels. PhD thesis. Ecole Nationale Superieure des Mines de Paris France, 2011.

42. Fournier, B., et al., Creep-Fatigue Interactions in a 9 Pct Cr-1 Pct Mo Martensitic Steel: Part II. Microstructural Evolutions. Metallurgical and Materials Transactions A, 2009. 40(2): p. 330-341.

43. Britishstandard:Metallicmaterials-fatiguetesting-strain-controlledthermo-mechanical fatiguetestingmethod, BSISO12111:2011(E).2011,BSIStandards Publication: UK.

44. A.H.Cottrell, "Dislocations and plastic flow in crystals”. Oxford University Press, 1953.

45. Radhakrisnan, V.M., On Bilinearity of Manson-Coffin Low Cycle Fatigue Relationship, NASA Technical Memorandum 105840. October (1992).

46. J.Lemaitre and J..L.Chaboche, Mechanics of Solid Materials. Cambridge University Press, , 25 Aug 1994. 